\title{
Chimeric Antigen Receptor-T Cells for Targeting Solid Tumors: Current Challenges and Existing Strategies
}

\author{
Lorraine Springuel $^{1}$. Caroline Lonez ${ }^{1}(1) \cdot$ Bertrand Alexandre $^{1}$. Eric Van Cutsem ${ }^{2}$. Jean-Pascal H. Machiels ${ }^{3}$. \\ Marc Van Den Eynde ${ }^{3} \cdot$ Hans Prenen ${ }^{4}$. Alain Hendlisz $z^{5}$. Leila Shaza ${ }^{5} \cdot$ Javier Carrasco $^{6}$. Jean-Luc Canon ${ }^{6}$. \\ Mateusz Opyrchal $^{7} \cdot$ Kunle Odunsi $^{7} \cdot$ Sylvie Rottey ${ }^{8} \cdot$ David E. Gilham $^{1} \cdot$ Anne Flament $^{1} \cdot$ Frédéric F. Lehmann $^{1}$
}

Published online: 30 July 2019

(c) The Author(s) 2019

\begin{abstract}
Chimeric antigen receptor-T cells (CAR-Ts) are an exciting new cancer treatment modality exemplified by the recent regulatory approval of two CD19-targeted CAR-T therapies for certain B cell malignancies. However, this success in the hematological setting has yet to translate to a significant level of objective clinical responses in the solid tumor setting. The reason for this lack of translation undoubtedly lies in the substantial challenges raised by solid tumors to all therapies, including CAR-T, that differ from B cell malignancies. For instance, intravenously infused CAR-Ts are likely to make rapid contact with cancerous B cells since both tend to reside in the same vascular compartments within the body. By contrast, solid cancers tend to form discrete tumor masses with an immune-suppressive tumor microenvironment composed of tumor cells and non-tumor stromal cells served by abnormal vasculature that restricts lymphocyte infiltration and suppresses immune function, expansion, and persistence. Moreover, the paucity of uniquely and homogeneously expressed tumor antigens and inherent plasticity of cancer cells provide major challenges to the specificity, potency, and overall effectiveness of CAR-T therapies. This review focuses on the major preclinical and clinical strategies currently being pursued to tackle these challenges in order to drive the success of CAR-T therapy against solid tumors.
\end{abstract}

Lorraine Springuel and Caroline Lonez contributed equally to this article.

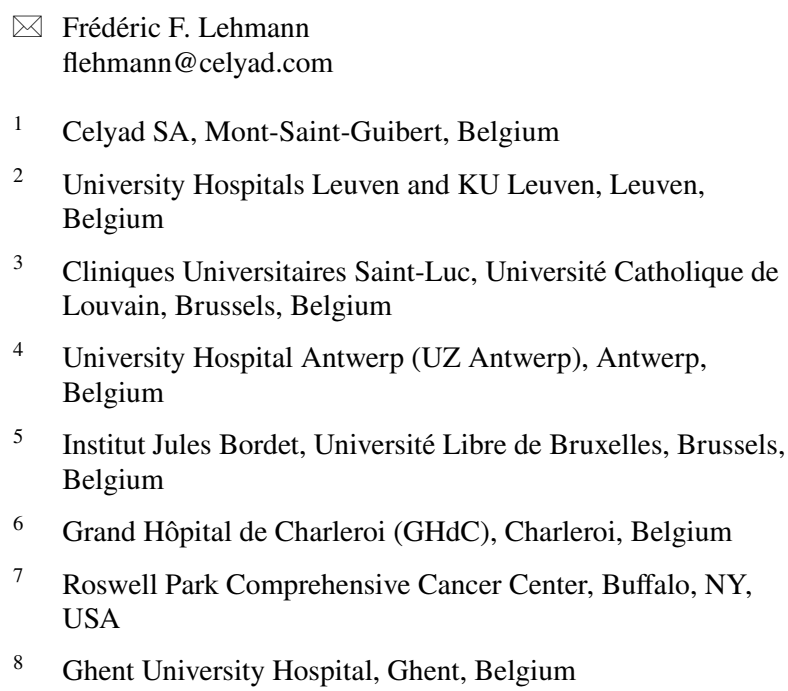

3 Cliniques Universitaires Saint-Luc, Université Catholique de Louvain, Brussels, Belgium

4 University Hospital Antwerp (UZ Antwerp), Antwerp, Belgium

5 Institut Jules Bordet, Université Libre de Bruxelles, Brussels, Belgium

6 Grand Hôpital de Charleroi (GHdC), Charleroi, Belgium

7 Roswell Park Comprehensive Cancer Center, Buffalo, NY, USA

8 Ghent University Hospital, Ghent, Belgium

\section{Key Points}

Chimeric antigen receptor-T cell (CAR-T) therapy for the treatment of solid tumors is currently being evaluated in approximately one-third of all CAR-T clinical trials.

CAR-T therapies targeting solid cancers have yet to demonstrate similar levels of clinical response as those being achieved in hematological indications.

Developing methods and technologies to overcome the immune-suppressive tumor environment, tumor accessibility and infiltration, as well as optimization of CAR-T function are the current focus of the CAR-T field in order to improve therapy for solid tumors.

\section{Introduction to the Chimeric Antigen Receptor-T Cell (CAR-T) Field}

Chimeric antigen receptors (CARs) are artificial fusion proteins that, when expressed on the cell surface, endow the engineered $\mathrm{T}$ cell with a pre-defined target specificity 
[1]. The CAR itself has developed through several generations, albeit generally based on the same configuration: an extracellular antigen-binding domain, usually employing an antibody-derived single-chain variable Fragment ( $\mathrm{scFv}$ ), linked through an extracellular spacer to a transmembrane domain and an intracellular $\mathrm{T}$ cell activation tail comprising different functional units. The core component of the CAR endodomain typically consists of the intracellular domain of the $\mathrm{T}$ cell co-receptor $\mathrm{CD} 3 \zeta$ containing three immunoreceptor tyrosine-based activation motifs (ITAMs) in tandem with, depending on the generation, none, one, or two costimulatory domains. Upon expression in a T cell, the CAR can engage its target antigen and thereby enable the lymphocyte to activate a plethora of effector responses resulting in targeted cell killing [2].

Whilst $\mathrm{T}$ cells use their endogenous $\mathrm{T}$ cell receptor (TCR) to bind specific proteins on target cells called the major histocompatibility complex (MHC), the expression of the CAR avoids this restriction and provides the real power to the approach in which the $\mathrm{T}$ cell can be directed to virtually any tumor target without MHC restriction. Consequently, while tumors evolve to avoid immune elimination through utilizing mechanisms that subvert the activity of the TCR, the CAR employs a targeting approach that in turn 'avoids the avoidance mechanism', making tumors again susceptible to T cell-mediated attack. Together, the breadth of targeting combined with the generic nature of the approach for any patient, given the lack of reliance on MHC, makes the CAR approach a potentially highly attractive therapy.

\section{NEW CASES IN US 2019 - PER ORGAN CLASS}

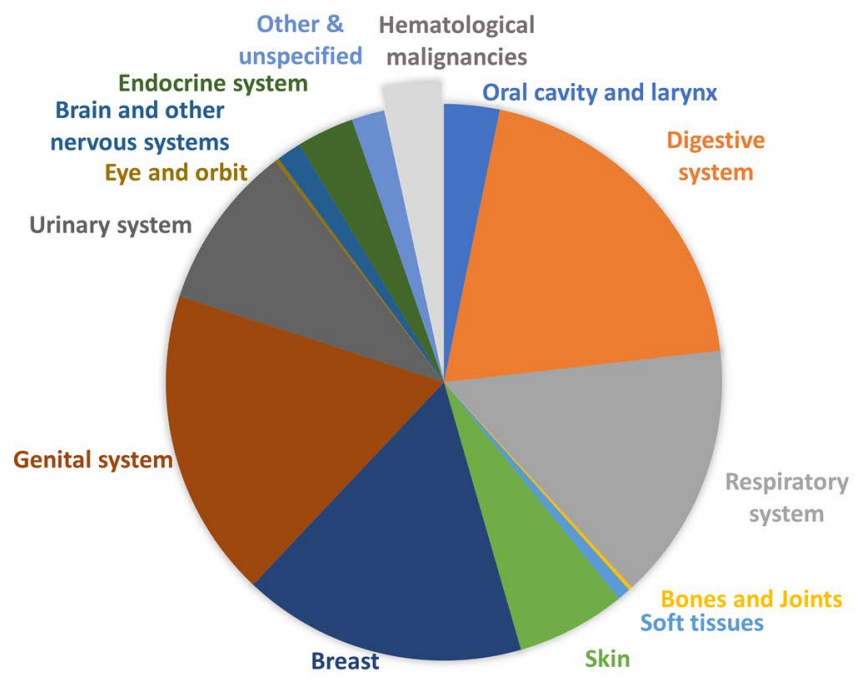

Fig. 1 Estimated proportion of new cancer cases in the USA in 2019 (left) and CAR-T clinical trials per organ class (right). Based on Cancer Facts and Figures, 2019 (American Cancer Society) [129] and
The reason why the approach is 'potentially' attractive relates to the target and the barriers that the CAR-T cell (CAR-T) has to overcome to engage and eliminate tumor cells. An ideal target is one that is highly expressed on transformed cells as compared to low or undetectable levels of expression on non-malignant healthy tissues. Yet, for the most part, such perfect targets do not exist due to the lack of truly tumor-specific targets. The targets most commonly available are typically over-expressed on transformed cells but also expressed at low levels on non-malignant tissues meaning that 'on-target, off-tissue' toxicity becomes a limiting factor. In the B cell situation, the CD19 target antigen is expressed solely on B cells meaning that the CAR-Ts will eliminate malignant and non-malignant $B$ cells. Whilst clearly not ideal, the lack of B cells is not considered to be life-threatening, with patients receiving immunoglobulin infusions to counter the lack of B cells in the treated patient.

To date, the most clinically investigated indications for CAR-T therapy are hematological malignancies [3, 4] (Fig. 1). CD19-directed CAR-T therapy has demonstrated impressive clinical responses in patients with advanced, chemotherapy-resistant leukemia and lymphoma, reaching up to $70-90 \%$ of minimum residual disease-negative complete remissions in some studies [5-8]. Two CD19-specific CAR-T treatments were recently approved by the US Food and Drug Administration (FDA) and the European Medicines Agency (EMA), namely Yescarta ${ }^{\mathrm{TM}}$ (axicabtagene ciloleucel) $[9,10]$ for patients with relapsed or refractory aggressive non-Hodgkin lymphoma and Kymriah ${ }^{\mathrm{TM}}$ (tisagenlecleucel) $[11,12]$ for patients with acute lymphoblastic

\section{CAR T TRIALS - PER ORGAN CLASS}

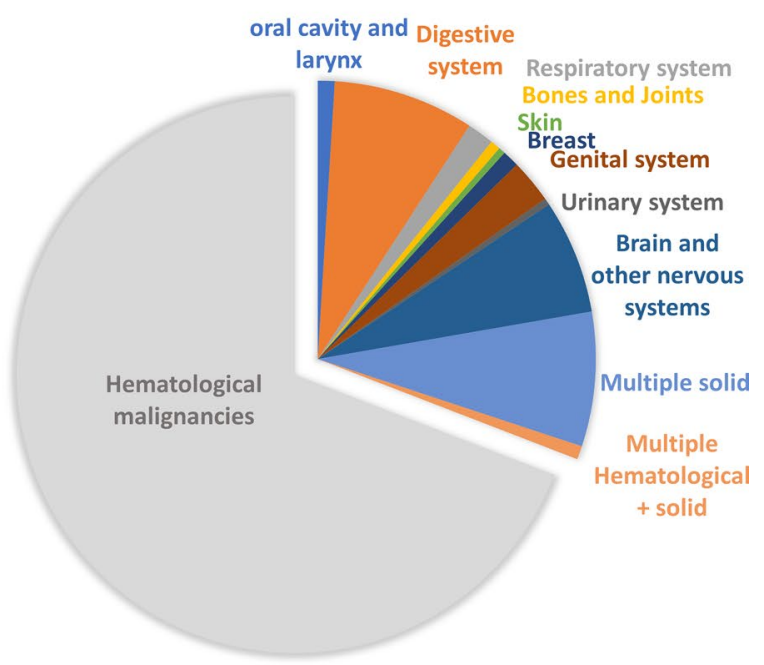

the U.S. National Library of Medicine (ClinicalTrials.gov; excluding long-term follow-up and retrospective studies). CAR-T chimeric antigen receptor $\mathrm{T}$ cell 
leukemia and diffuse large B cell lymphoma [13, 14]. The success story of CAR-T therapies in hematological malignancies has nurtured the hope of extending the use of these 'living drugs' to further cancer indications, including solid tumors, especially considering the proportion of new cases of patients with solid tumors per year as compared with hematological tumors (Fig. 1).

When considering the majority of solid tumors, much effort is ongoing worldwide to determine patient-specific antigens (neo-antigens) that can be targeted, but this approach is not well-suited to the generic CAR-T approach where a single CAR can be used in the majority of patients with a specific tumor indication. Consequently, many of the targets in current use for solid tumor CAR-T therapy have been identified through antibody-directed therapies and are usually expressed to some degree on non-malignant tissue. As discussed later, this means either titrating the CAR-T therapy to achieve a window of therapy without toxicity or the development of methods that can more directly control the CAR itself to negate the possibility of on-target, offtissue toxicity.

Beyond the question of target, there is increasing clarity concerning the specific challenges raised by solid tumors to CAR-T therapy. This review discusses these major obstacles and explores preclinical and clinical efforts aiming to overcome these hurdles and drive the success of CAR-T therapy in the solid cancer area where, to date, substantive levels of clinical response are still lacking (see Sect. 3).

\section{Overcoming the Barriers Raised by Solid Tumors Against T Cells}

The impressive clinical response of CD19-specific CAR-T likely relies on the high-level expression of the targeted antigen on the tumor cells as well as the peripheral distribution of the lymphoid cancer cells enabling accessibility and susceptibility to T cell-mediated elimination. Unlike B cell malignancies, solid cancers sculpt a tumor microenvironment (TME) that not only restricts lymphocyte trafficking and access to the entire mass of the solid tumor [15] but also downregulates their activity, expansion, and persistence at the tumor site $[16,17]$. The TME represents an intricate cellular and molecular immunosuppressive network formed by aberrant vasculature, stromal cells, immune cells (including regulatory $\mathrm{T}$ cells [Tregs]/myeloid-derived suppressor cells [MDSCs]/tumor-associated macrophages [TAMs]), and extracellular matrix-containing inhibitory factors, and is characterized by oxidative stress, nutritional depletion, acidic $\mathrm{pH}$, and hypoxia [18]. Beyond the immunosuppressive TME and the paucity of uniquely and homogeneously expressed tumor antigens, the inherent plasticity of cancer cell populations and the selective outgrowth of target antigen-loss variants add an additional layer of complexity, providing further challenges to the effectiveness of CAR-T therapies.

To face those challenges, additional engineering of CARTs and the use of combination therapies hold the potential to endow therapeutic cell products with novel attributes necessary to overcome immunosuppressive aspects of the TME. However, since solid tumors are protected from immune attack by cumulative defenses, the abrogation of only one factor may not produce a significant change in the effectiveness of the overall cellular immunotherapy. Moreover, it is crucial that efforts to enhance the functionality of CAR-Ts do not compromise safety and should ideally be coupled with stringent tools that allow for spatial and temporal control of their activity and persistence after deployment into the patient [19].

The following sections describe some of the approaches that are being considered to surmount challenges faced when treating solid tumors with CAR-T therapies, with a focus on strategies that concurrently resolve more than one evasion mechanism and that are widely applicable to different solid tumor indications.

\subsection{Increasing the Homing of CAR-Ts at the Tumor Site}

Following infusion into the systemic circulation, CAR-Ts are faced with the immediate obstacle of localizing to and infiltrating into the tumor parenchyma. Homing and tissue infiltrating is a multistep process governed by the expression and pairing of adhesion molecules present on both the $\mathrm{T}$ cells and the inflamed vasculature that act sequentially to mediate attachment, rolling, and extravasation of circulating lymphocytes towards a chemokine gradient produced by tumor cells. However, aberrant expression of adhesion molecules on the tumor endothelium as well as $\mathrm{T}$ cell chemokine receptor/tumor-associated chemokine incompatibility and hydrostatic pressure result in inefficient intratumoral $\mathrm{T}$ cell infiltration potentially causing treatment-related toxicities due to the accumulation of transferred cells in inflamed normal tissues, such as in the case of injury or autoimmune disease [20].

Several preclinical models demonstrated that the forced expression of a chemokine receptor complementary to tumor-associated chemokines enhanced the ability of CARTs to traffic to and expand at the tumor site, consequently improving their antitumor efficacy $[21,22]$. However, applicability of this approach is restricted by the fact that the chemokine landscape can be extremely heterogeneous both across disease entities and patients, underscoring the need to identify specific receptor candidates to enhance $\mathrm{T}$ cell infiltration into different cancer types [23]. Furthermore, chemokines are not restricted to the tumors, suggesting there 
could be diversion of the cells to other anatomical locations where the specific chemokine is present.

Although not always technically achievable, loco-regional delivery of CAR-Ts reduces trafficking restrictions without additional engineering while circumventing the transient pulmonary sequestration of intravenously administered $\mathrm{T}$ cells $[24,25]$. In mouse models, intraperitoneal or intrapleural administration of CAR-Ts outperformed systemic infusion and, surprisingly, also impacted disseminated tumor sites attributed to a benefit of $\mathrm{T}$ cell activation shortly after delivery [26, 27]. Accordingly, several clinical trials are examining the safety of administration of loco-regional CAR-T therapies (discussed in Sect. 3), even though infiltration within solid tumor masses is not always improved by loco-regional delivery. Finally, nanoparticles expressing CARs, which bind to and re-program peripherally circulating $T$ cells in vivo, were also recently developed to increase selectivity and distribution to distant organs [28].

\subsection{Neutralization of Immunosuppressive Mediators within the Tumor Microenvironment}

Once they have successfully invaded the tumor parenchyma, CAR-Ts then have to contend with a highly hostile milieu for $T$ cell antitumor effector function, replete with suppressive mediators (transforming growth factor [TGF]- $\beta$, interleukin [IL]-10, IL-4) and inhibitory molecules (programmed deathligand 1 [PD-L1], cytotoxic T lymphocyte antigen 4 [CTLA4], Fas-ligand [FASL]). Apart from TME remodeling, which should be induced by the combination with chemotherapy agents, a more specific combination strategy with programmed death 1 (PD-1)/PD-L1 or CTLA-4-blocking antibodies (the so-called checkpoint inhibitors commonly used in clinical studies with excellent outcomes [29]) and CAR-Ts can therefore potentially augment antitumor effects against solid tumors [17, 30, 31]. CAR-Ts can also be shielded to intrinsically resist immunosuppressive signaling by disrupting endogenous expression of inhibitory receptors through gene editing or transgenic expression of a dominant-negative form of those receptors or inhibitory antibodies [32-36]. However, the abrogation of immunosuppressive signaling may be insufficient, prompting additional investigations into alternative approaches that can turn TME limitations into advantages for the transferred CAR-Ts. Co-expression of a chimeric receptor that converts an immunosuppressive signal into an immunostimulatory one could also extend CAR-T engineering beyond neutralization of inhibitory ligands to the active reversal of their effects. Exchanging the endodomain of inhibitory receptors such as IL-4 receptor (IL4R) or PD-1 with signaling domains derived from stimulatory receptors (IL-7 receptor [IL-7R], CD28, or 4-1BB) improved in vivo antitumor efficacy of tumor-directed T cells [37-39]. Importantly, CAR-T activation could be confined to the tumor site since triggering would require exposure to both the specific antigen and the tumor-derived factor. In addition to promoting function and survival of the modified T cells, the use of inhibitory-to-stimulatory switch receptors might present the advantage of depriving the TME of an immunosuppressive factor, potentially providing collateral benefits to endogenous exhausted tumor-infiltrating lymphocytes (TILs) [39, 40]. Although those additional engineering strategies proved effective in murine models, selective neutralization of a single immunosuppressive pathway might render a functional, albeit transient, antitumor state and fall short of preventing long-term relapse due to the upregulation of multiple inhibitory receptors by activated $\mathrm{T}$ cells, thus limiting the window of time that the CAR-Ts exert their function. On the other hand, as those receptors are important regulators of $\mathrm{T}$ cell homeostasis, the impact of such modifications on $\mathrm{T}$ cell effector function in humans remains to be determined, as well as any potential impact of the leverage of immune brake that could lead to uncontrolled lymphoproliferation or other immune-related adverse events.

Another methodology addresses the unfavorable TME by using CAR-Ts as production vehicles that secrete proinflammatory cytokines, such as IL-12 or IL-18, into the targeted tumor tissue, tuning the $\mathrm{T}$ cell response into a more acute one [41]. Beyond auto-stimulation of the transferred cells [42], release of effector cytokines by those so-called 'TRUCKs' (T cells Redirected for Universal Cytokine Killing) was shown to reshape the TME through multiple paracrine mechanisms including recruitment of additional tumorreactive cells from the innate and adaptive immune systems [43-45]. As tumor cell lysis by TRUCKs can generate new antigen-specific lymphocytes via epitope spreading, the concomitant local release of effector cytokines will support the effector function of these host immune cells and also recruit and activate innate immune cells [46, 47]. Despite all the expected benefits, the systematic delivery of proinflammatory cytokines may lead to significant toxicities [48], underscoring the critical need to restrict cytokine production to the lesion site by using a promoter that becomes active only upon CAR engagement. In addition, inducible expression systems are more likely to constrain cytokine levels within a therapeutic range as overactivation of $\mathrm{T}$ cells by supra-therapeutic cytokine levels will foster counterproductive exhaustion. However, in early-phase clinical trials, adoptive transfer of TILs genetically engineered to secrete IL-12 at the tumor site resulted in severe toxicities [49]. Therefore, the use of less stimulatory cytokines such as IL-18 might present a safer option as this cytokine was given intravenously at high biologically active doses to cancer patients with no occurrence of dose-limiting toxicities [50]. In addition, integration of suicide genes or safety switches is another option to mitigate toxicity potentially induced by such strategies (see Sect. 2.5). 
Since emerging nanoscale-targeted drug carriers are able to remodel the TME without giving rise to the systemic toxicity, CAR-engineered $\mathrm{T}$ cells were also employed as active chaperones to successfully deliver adenosine receptor antagonist-loaded cross-linked multilamellar liposomal vesicles to TILs deep in the immunosuppressive TME, in order to prevent or rescue the emergence of hypofunctional CAR-Ts within the TME [51].

\subsection{Boosting In Vivo CAR-T Expansion and Persistence Capacities}

While the in vivo cell expansion and effectiveness of CD19 CAR-Ts seem to correlate in certain studies using CAR-T in hematological malignancies [52, 53], it is generally considered that the intrinsic qualities of infused lymphocytes are some of the determinants of success in CAR-T therapies. The ex vivo manipulation of $\mathrm{T}$ cells provides a unique opportunity to select for cellular subsets with enhanced potential for mounting durable antitumor responses [54]. Selection of $\mathrm{CD}^{+}$cytotoxic cellular subsets, ratios of CD4:CD8, or use of natural killer cells may increase broad effector activity [46, 55]. Although the 'seed' population optimally suited for the production of long-lived CAR-Ts is still a matter of debate, an emerging consensus postulates that less-differentiated phenotypes such as cells presenting naïve and central memory phenotypes have superior proliferative capacity and sustained survival and, as such, are more effective at regressing established tumors than latedifferentiated effector memory and effector $\mathrm{T}$ cells [56]. Building on this concept, there is growing interest in developing protocols to conduct large-scale $\mathrm{T}$ cell amplification, while simultaneously preserving the functional features of early-memory T cells [57]. It was shown that reducing the duration of ex vivo culture to 3-5 days yielded less-differentiated cells with enhanced therapeutic potential compared with cells expanded using standard 9- to 12-day protocols [58]. An alternative strategy to limit cell differentiation during CAR-T manufacturing is the pharmaceutical blockade of the phosphoinositide 3-kinase (PI3 K)/AKT axis playing an integral role in $\mathrm{T}$ cell activation downstream of the TCR and co-stimulatory molecules $[59,60]$. Another option would be to substitute IL-7 and IL-15 for IL-2 as the growth factor support during ex vivo generation of CAR-T products as this cytokine combination was shown to enrich for $\mathrm{T}$ memory stem cells [61]. In preclinical models, CAR-Ts expanded in IL-7 and IL-15 showed superior persistence and antitumor activity compared with counterparts grown in IL-2 [62].

Holding back the acquisition of full effector capacity ex vivo by the reduction of culture duration or modulation of $\mathrm{T}$ cell differentiation represents relatively easily translatable and widely applicable ways for the generation of earlymemory CAR-Ts. The question is whether these cells have the therapeutic potential to be effective at lower infusion doses, potentially mitigating acute toxicity and commensurately trimming production costs [60].

The evolution of CAR design, to date, has focused predominantly on increasing signaling outputs through combinatorial modules of co-stimulatory domains fused in series to ITAM-bearing CD3 $\zeta$ activation domain [63]. However, there is now a growing appreciation that functional tuning of CAR signaling has an upper limit. Above this limit, gains in the magnitude of effector outputs are negated by augmentation of $\mathrm{T}$ cell differentiation, exhaustion, and activation-induced cell death (AICD) [20, 21]. Accordingly, the next challenge for future CAR generations will be to calibrate CAR activation in order to achieve an optimal balance between effector and memory programs in T cells. Optimized configurations of CARs are being investigated to better recapitulate the dynamic process of natural $\mathrm{T}$ cell activation and co-stimulation, sharply differing from the 1:1 stoichiometry constraint within CAR designs currently under clinical investigation. For example, the expression of a CD28-based CAR along with 4-1BB ligand resulted in higher therapeutic efficacy, reconciling tumoricidal function afforded by CD28 co-stimulation with increased T cell persistence afforded by 4-1BB engagement [64]. Recently, a CD28-based CAR containing a single functional ITAM was shown to favor in vivo persistence of highly functional CAR-Ts, balancing the replicative capacity of long-lived memory cells with the acquisition of strong antitumor effector functions [65]. However, the optimal construct will likely depend on several factors, including affinity (avidity) for target, tumor access, and the type of TME.

Therefore, while several options to improve both persistence and expansion capacities of CAR-Ts are currently being investigated, no universal solution has yet been identified. To this end, the empirical testing of CARs remains the only option to evaluate the different potential schema of CAR/T cell phenotype/additional functionality such as TRUCKs.

\subsection{Improving Targeting of Heterogeneous Tumors}

Although not specific to solid tumors, due to the paucity of truly tumor-restricted antigens in solid tumor tissues, CARTs will need to become capable of recognizing patterns of gene expression that are different between normal and malignant cells, rather than relying on single-though highly specific-antigenic markers. One approach that was investigated is to engineer CAR-Ts with dual specificity, whereby two receptors targeting distinct antigens act as 'AND/NOT' Boolean logic gates $[66,67]$ in order to prevent toxicity while maintaining efficacy, rather than irreversibly deleting CAR-Ts that are toxic against both tumor and host. The 'AND' gates require the successful recognition of a set of 
pairwise upregulated tumor antigens by two different CARs to initiate full immune cell functions $[68,69]$, whereas 'NOT' gates employ receptors that prevent $\mathrm{T}$ cell activation when engaging antigens found on healthy tissues [70]. While Boolean logical sensing may enhance the specificity of CAR-Ts towards tumors, this approach is still limited by the fixed antigen specificity of conventional CAR design, and by the fact that the therapeutic window will require an optimal expression pattern of multiple targets while a single target antigen loss could severely disable the system.

An alternative to this classical antibody-based CAR limitation would be to harness the multiple ligand-binding ability of physiological immune receptors such as NKG2D (natural killer group 2 member D). NKG2D recognizes several stress-induced ligands expressed within the TME of cancers from diverse origins, not only on the tumor cells themselves but also on tumor neovasculature and tumorassociated immune cells. Thus, a CAR bearing NKG2D as the targeting moiety holds the potential to eliminate a broad array of cancers, simultaneously altering the tumor and its supportive framework [71-73]. A second ligand-based CAR approach targets the ErbB receptor family, for which at least one member is expressed in $88 \%$ of solid tumors [74-77].

Another possibility is to target the CAR-Ts towards antigens expressed on tumor stroma and vasculature, which are expressed by multiple tumor types and would increase the homing into the TME $[78,79]$.

\subsection{Mitigating Toxicity}

A first option to mitigate the potential on-target, off-tissue toxicity of CAR-Ts is the use of CAR-Ts with reduced persistence capacities such as transiently expressed CARs using non-viral approaches including messenger RNA (mRNA) electroporation [80], sleeping beauty transposition [81], and/ or a multiple-dose schedule of short persisting CAR-Ts to control engraftment $[80,82]$. Furthermore, the hypofunctionality of CAR-Ts within the TME may also be overcome by a multiple-dosing approach $[16,17,83]$.

Equipping CAR-Ts with properties aimed at enhancing their potency or their infiltration into tissues should ideally be coupled with stringent safety attributes that allow for temporal regulation of activity or persistence of infused cells in the patients. Co-expression of suicide genes encoding surface molecules or enzymes conferring susceptibility to antibody- or drug-mediated cell death allows for selective and irreversible depletion of the transduced T cells after infusion into the patients [84-86].

To avoid the irrevocable elimination of potentially therapeutic cells, several platforms have been developed to repeatedly turn on and off CAR-T activity at will after reinfusion into the patients (called 'safety switch' or 'advanced cell programming technology') to prevent and/or limit the likelihood of toxicity. These 'switchable' CAR-Ts are not directed to a cell surface target antigen and are per se inert but become operative strictly in the presence of a bispecific adaptor molecule that mediates formation of the immunological synapse between the target cancer cell and the lymphocyte [87-92]. After rapid elimination of the adaptor molecule from the peripheral blood, CAR-Ts automatically turn off, thus providing a self-limiting safety switch. Moreover, the modularity of the switchable CAR-T approach provides options for altering specificity post-adoptive transfer by delivery of adaptor molecules targeting different antigens together with one single cellular product, which may be an effective strategy for addressing antigen loss relapse and heterogeneity of tumor populations. Furthermore, the ability to titrate CAR-T activity in vivo through adaptor molecule dosing paradigms offers the opportunity to achieve a gradual clearance of cancer cells, minimizing acute toxicity in high tumor burden patients. Finally, low-dose treatment with an adaptor molecule maintained a larger central memory compartment within CAR-Ts than did high-dose regimens, with the potential to boost in vivo cell endurance, as discussed earlier. However, the potential drawback of this approach lies in the need for multiple costly reagents and the challenge of ensuring that the engager and CAR-T meet in the correct location at a concentration of each entity sufficient to drive a therapeutic response. Within the parenchyma of a solid tumor, this would likely be a major dosing challenge.

\subsection{Combination of Approaches into One Cellular Product}

The future of CAR-T cellular therapies for solid tumors resides in the alliance of wisely selected complementary approaches that will generate a cellular product with enhanced tissue penetration and homing, well-balanced effector and memory outputs, enhanced specificity/safety, and the ability to resist TME immunosuppression while concurrently reviving the endogenous host immune system (see Table 1). Using healthy donor cells instead of each patient's cells, i.e., development of allogeneic approaches with a decreased risk of graft-versus-host disease (GvHD) and management of host-versus-graft disease (HvGD), may provide answers to some of these issues. The use of a single donor should provide a greater degree of product consistency, while the likely youthful healthy donor would potentially provide a $\mathrm{T}$ cell product that has not been skewed by the long-term exposure to tumor cells as would be the case for an autologous product. From a practical perspective, allogeneic CAR-T therapy may also provide economic benefits through reduced per patient costs and the fact that patients would not need to wait for the length of the manufacturing period before receiving the product. Earlier treatment of patients with acute disease could be of critical importance 


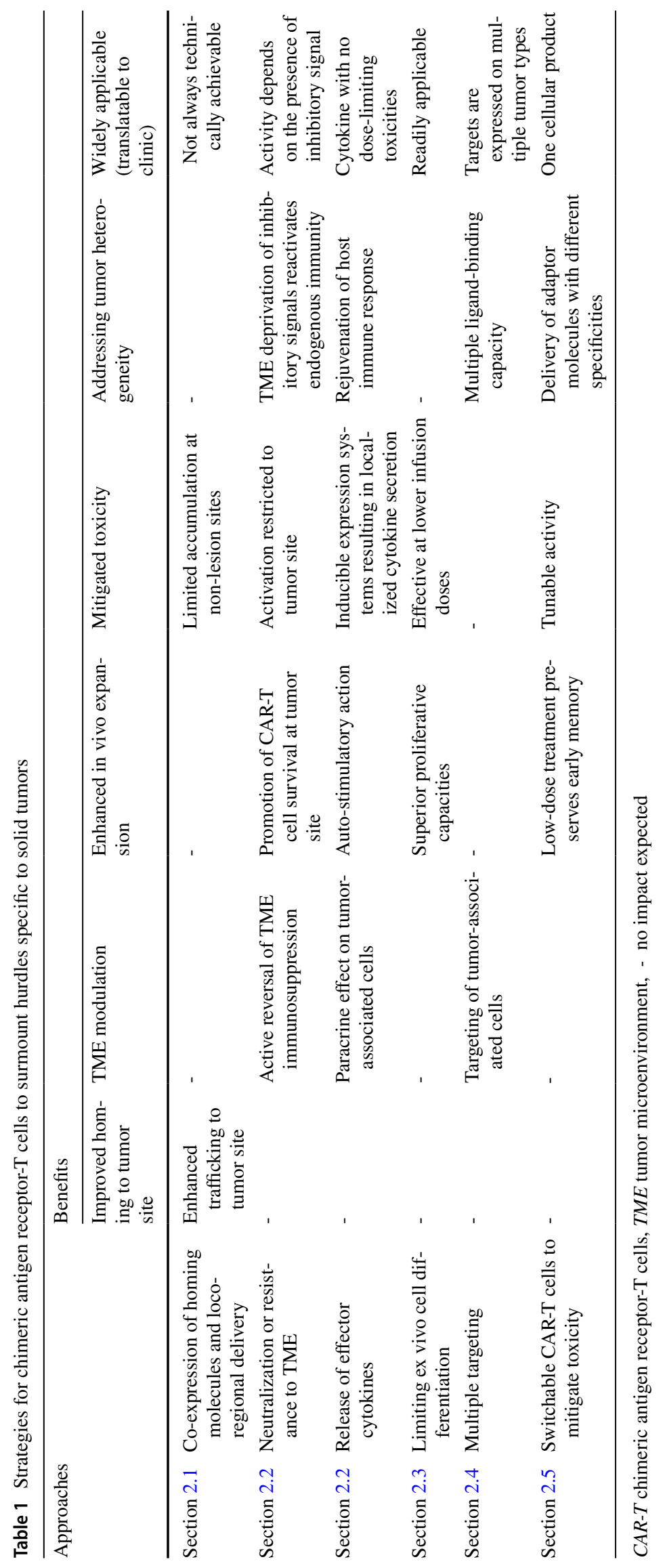


with respect to therapeutic readouts. One approach being pursued to generate an allogeneic CAR-T product is the complete elimination of TCR and human leukocyte antigen (HLA) molecules usually performed by gene-editing techniques [93, 94].

Yet, a major task is the transition from proof-of-concept studies employing human tumor cell line xenografts into immunocompromised mice to the development of clinically implementable technologies. Indeed, the clinical predictive power of such experimental systems is challenged by the fact that they imperfectly reflect the structural complexity and heterogeneity of established solid human tumors, poorly inform about potential cross-reactivity against healthy human tissues, and provide limited insights about how CAR-Ts interface with the host immune components. Patient-derived xenografts may represent more clinically relevant models but suffer from a variable engraftment rate and poor availability [95]. In addition, stromal cells from the original human tumor cannot proliferate continuously and are replaced by cells derived from the recipient mouse [96], thereby preventing investigations into the impact of therapy on TME. Ultimate validation of which combinatorial approaches or defined $\mathrm{T}$ cell subsets composition will achieve sustainable effective responses in the human context will only come from future clinical trials carried out to evaluate the resulting conclusion.

\section{Current Treatment of Solid Tumors in the Clinic}

Based on the first successes obtained with hematologic indications, and apart from the optimizations of the costimulatory domains and overall CAR vector construct and viral vector selection, the majority of clinical studies targeting solid tumors did not further modify the construct, the ex vivo cell culture conditions, or the administration procedures, nor did they use combinations to specifically counteract the hurdles raised by solid tumors. Early studies targeting solid tumors with a single intravenous infusion of first- or second-generation CAR-Ts reported little evidence of clinical effectiveness, while there was some evidence of on-target, off-tumor toxicity seen using CAR-Ts targeting carbonic anhydrase-IX [97, 98] in renal cell carcinoma or HER2 (human epidermal growth factor receptor 2)/neu in colorectal cancer [99], which further limited the development of CAR-Ts in the solid tumor field.

As of May 2019, around 160 completed or ongoing CAR-T clinical trials registered with the US National Library of Medicine (ClinicalTrials.gov) are targeting solid tumors (Fig. 1) (64\% of them in phase I, $30 \%$ in phase I/ II, $3 \%$ in phase II, $2 \%$ in long-term follow-up, and $1 \%$ retrospective studies) over a total of $\sim 510$ clinical trials in the CAR-T field. The most investigated targets are mesothelin, GD2 (disialoganglioside), HER2, MUC1 (mucin 1), CEA (carcinoembryonic antigen), GPC3 (glypican 3), and EGFRvIII (variant III of the epidermal growth factor receptor [EGFR]) (Fig. 2) and several companies that are currently developing CAR-T approaches for solid tumor indications have reported some preliminary clinical data (Tables 2, 3).

In total, only 61 trials (of which 51 are still ongoing) are evaluating one or two strategies specific to targeting solid tumors, with loco-regional administration being the most represented option, followed by TME neutralization (Fig. 2).

Loco-regional delivery (detailed in Sect. 2.1) is being or was investigated in 22 trials and is the only option that, to date, has demonstrated clinical activity and, in addition, provides a way to circumvent the potential on-target, offtumor toxicities by confining transferred cells within their targeted organs. Glioblastoma is, by far, the indication where the results were the most encouraging. Multiple intracranial infusions (to bypass the blood-brain barrier and target tumor cells throughout the entire central nervous system) of first-generation IL-13R $\alpha 2$-specific CAR-Ts led to transient anti-glioma responses and an encouraging duration of overall survival in the first three patients with recurrent glioblastoma multiforme (GBM) treated in the trial [100]. A recent case report demonstrated that repeated intracavitary infusions of second-generation IL-13R $\alpha 2$-specific CAR-Ts further demonstrated regression of all intracranial and spinal tumors, lasting for 7.5 months in one 50-year-old patient with recurrent multifocal GBM [101]. Of 16 evaluable patients with GBM treated with HER2-specific CARs, one had a partial response lasting for more than 9 months and seven had stable disease (SD) ranging in duration between 8 weeks and 29 months [102] (sponsored by Mustang Bio).

The next most important strategies being investigated are approaches to neutralizing or resisting the effects of the TME (18 trials) and/or reverting the TME to a stimulatory environment through the intrinsic release of cytokines (six trials) (see Sect. 2.2 for both approaches). As an example, one trial run by the Memorial Sloan Kettering Cancer Center and targeting pleural mesothelioma patients (recently licensed by Atara) with intrapleural administrations of mesothelin-targeting CAR-Ts observed two complete responses (CRs) out of 14 patients after combination with a checkpoint inhibitor [103].

A good example of a trial on a CAR-T that can mitigate toxicity (approach detailed in Sect. 2.5) is Bellicum Pharmaceuticals' autologous prostate stem cell antigen (PSCA)targeting CAR-T product (BPX-601). This CAR-T employs a rimiducid-inducible myeloid differentiation primary response 88 (MyD88)/CD40 co-activation switch to augment $\mathrm{T}$ cell proliferation and persistence, which provides control over the degree of activation of the CAR-Ts through 


\section{SOLID CAR T CLINICAL TRIALS - PER TARGET}

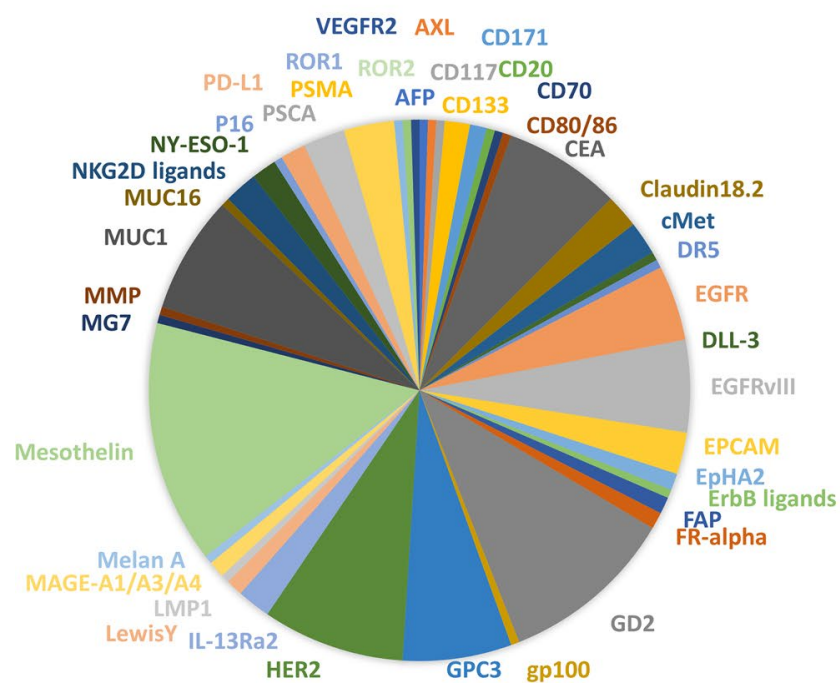

Fig. 2 CAR-T clinical trials targeting solid tumors. Based on the US National Library of Medicine (ClinicalTrials.gov; excluding longterm follow-up and retrospective studies). AFP $\alpha$-fetoprotein, $C A R$ chimeric antigen receptor, $C A R-T$ chimeric antigen receptor $\mathrm{T}$ cell, $C E A$ carcinoembryonic antigen, $D L L-3$ delta-like protein $3, D R 5$ death receptor 5, EGFR epidermal growth factor receptor, EGFRvIII variant III of the epidermal growth factor receptor, EPCAM epithelial cell adhesion molecule, EpHA2 Ephrin type A receptor 2, FAP fibroblast activation protein, $F R$-alpha folate receptor- $\alpha, G D 2$ disialoganglioside, gp100 glycoprotein 100, GPC3 glypican 3, HER2 human

adjustments to the schedule of rimiducid administration, but still in a tumor-dependent manner. Results from a phase I study evaluating BPX-601 in PSCA-positive metastatic pancreatic, gastric, or prostate cancer patients with or without prior preconditioning were presented at the American Association of Clinical Oncology (ASCO) meeting in 2019 [104] and reported rimiducid-dependent cell expansion, persistence, and cytokine secretion with no dose-limiting toxicity or cytokine release syndrome. After BPX-601 + rimiducid (15 patients treated), the best responses were eight SD and three progressive disease (one patient was non-evaluable). The trial is still ongoing with a more complete lymphodepleting regimen.

Other encouraging results were observed in clinical trials that include a combination of strategies (described in Sect. 2.6). A first example is a trial targeting pediatric neuroblastoma with single or multiple intravenous infusions of CAR-T-specific subpopulations (approach detailed in Sects. 2.3 and 2.5). There was one CR in the six patients treated with three intravenous infusions of $\mathrm{CD} 8^{+}$cytotoxic $\mathrm{T}$ lymphocytes co-expressing a CD171-targeting CAR and a selection-suicide expression enzyme, followed by additional treatment with salvage chemotherapy [105]. Similarly, three of 11 high-risk neuroblastoma patients with active disease achieved CR following infusions of Epstein Barr
SOLID CAR T CLINICAL TRIALS - PER APPROACH

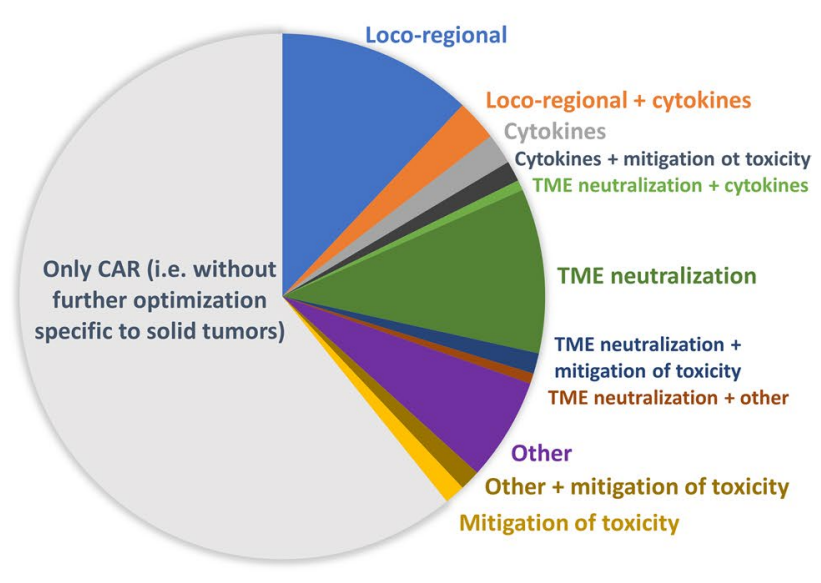

epidermal growth factor receptor $2, I L-13 R \alpha 2$ interleukin-13 receptor 22, LMP1 latent membrane protein 1, MAGE melanoma associated antigen, $M M P$ matrix metalloproteinase, $M U C 1$ mucin $1, N K G 2 D$ natural killer group 2 member D, NY-ESO-1 New York esophageal squamous cell carcinoma $1, P D-L 1$ programmed death-ligand 1, PSCA prostate stem cell antigen, PSMA prostate-specific membrane antigen, ROR $1 / 2$ receptor tyrosine kinase-like orphan receptor $1 / 2$, $T M E$ tumor microenvironment, VEGFR-2 vascular epidermal growth factor receptor-2

virus-specific cytotoxic $\mathrm{T}$ lymphocytes and $\mathrm{CD} 3$-specific antibody OKT3-activated T cells expressing GD2-targeting CAR-Ts, and persistence of cells beyond 6 weeks was associated with superior clinical outcome [106, 107].

Kings College, London has developed another combined approach with genetically engineered T cells (T4 CAR-Ts or LEU-001), which co-express two chimeric receptors: one CAR-T specific for ErbB ligands (HER2, HER3, and EGFR) and a second chimeric cytokine receptor $(4 \alpha \beta)$ which converts the IL-4 signal into a strong and selective growth signal, i.e., a CAR-T product that combines several approaches: multiple targeting and reshaping of the TME through release of pro-inflammatory cytokines (see Sects. 2.2, 2.4, and 2.6). A clinical study (ClinicalTrials.gov identifier NCT01818323) is currently evaluating intratumoral administration of T4 CAR-Ts for patients with head and neck squamous cell carcinoma without prior lymphodepletion [108, 109]. Results made public at the CAR-T Congress EU in January 2019 revealed nine of 15 injected patients with SD, with potential survival improvement. One patient received further treatment with the anti-PD-1 inhibitor pembrolizumab and was in CR 2.5 years after pembrolizumab treatment, suggesting a combination of their CAR-T therapy and an anti-checkpoint inhibitor might be the way to improve efficacy. 


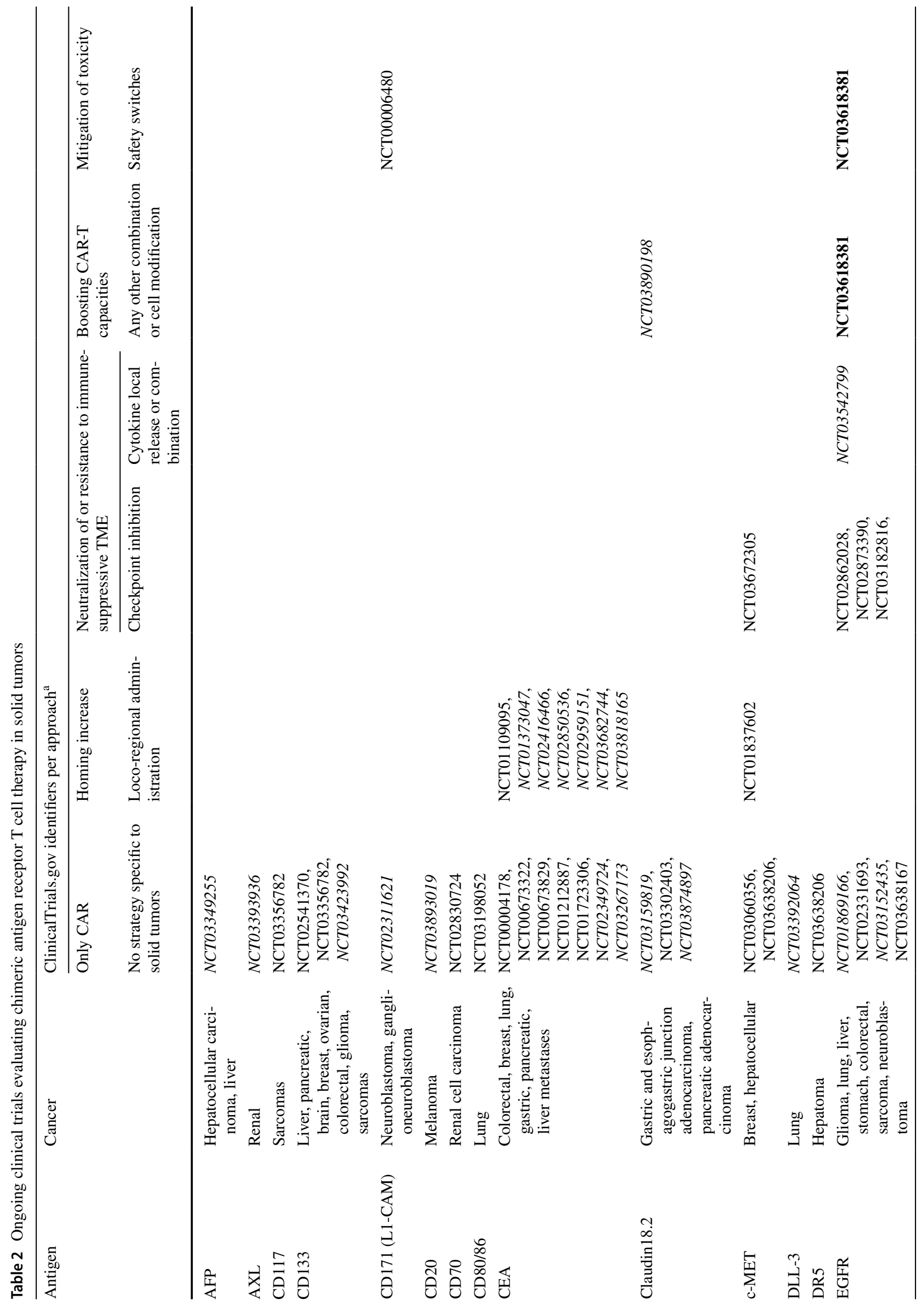




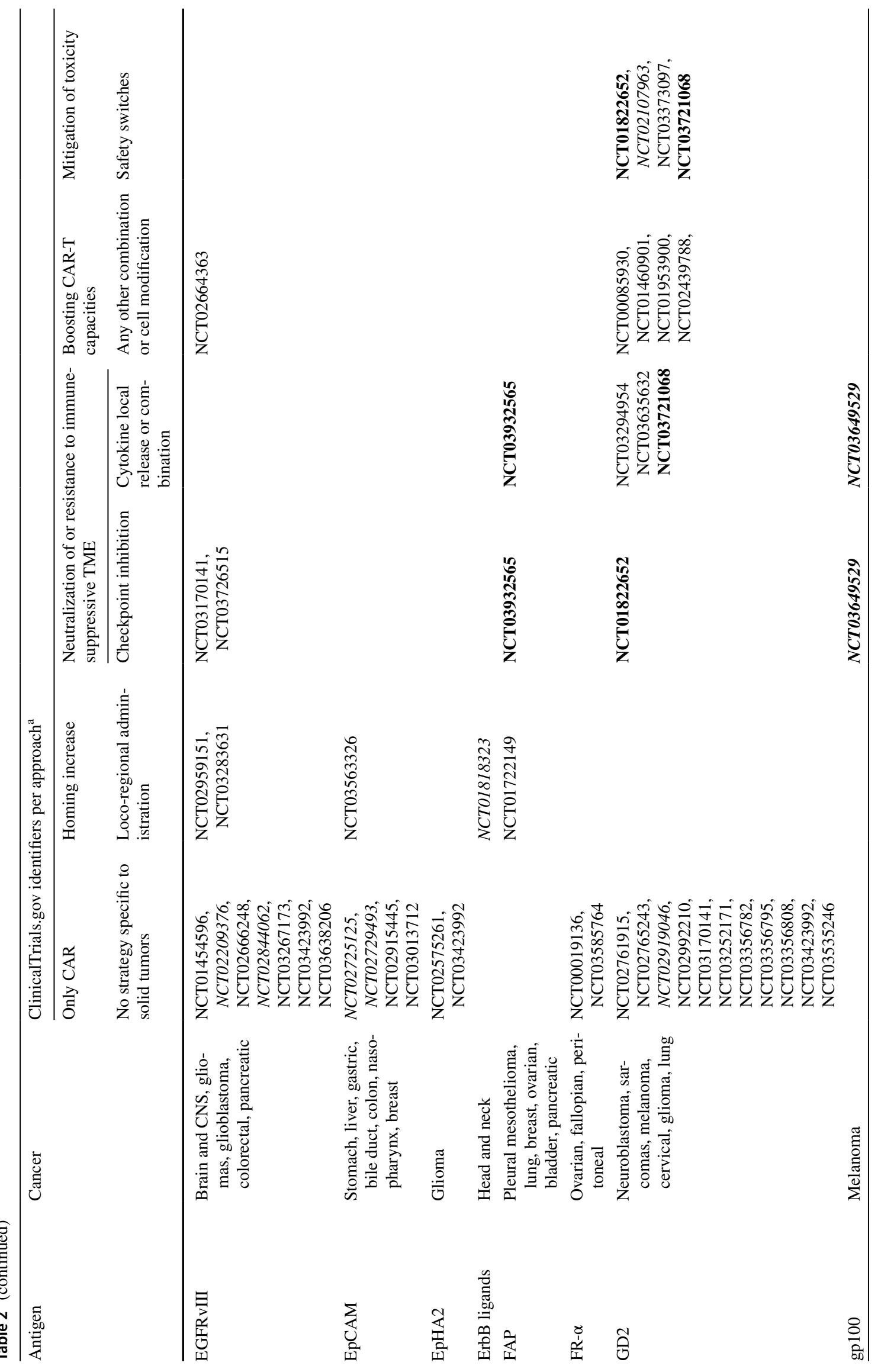




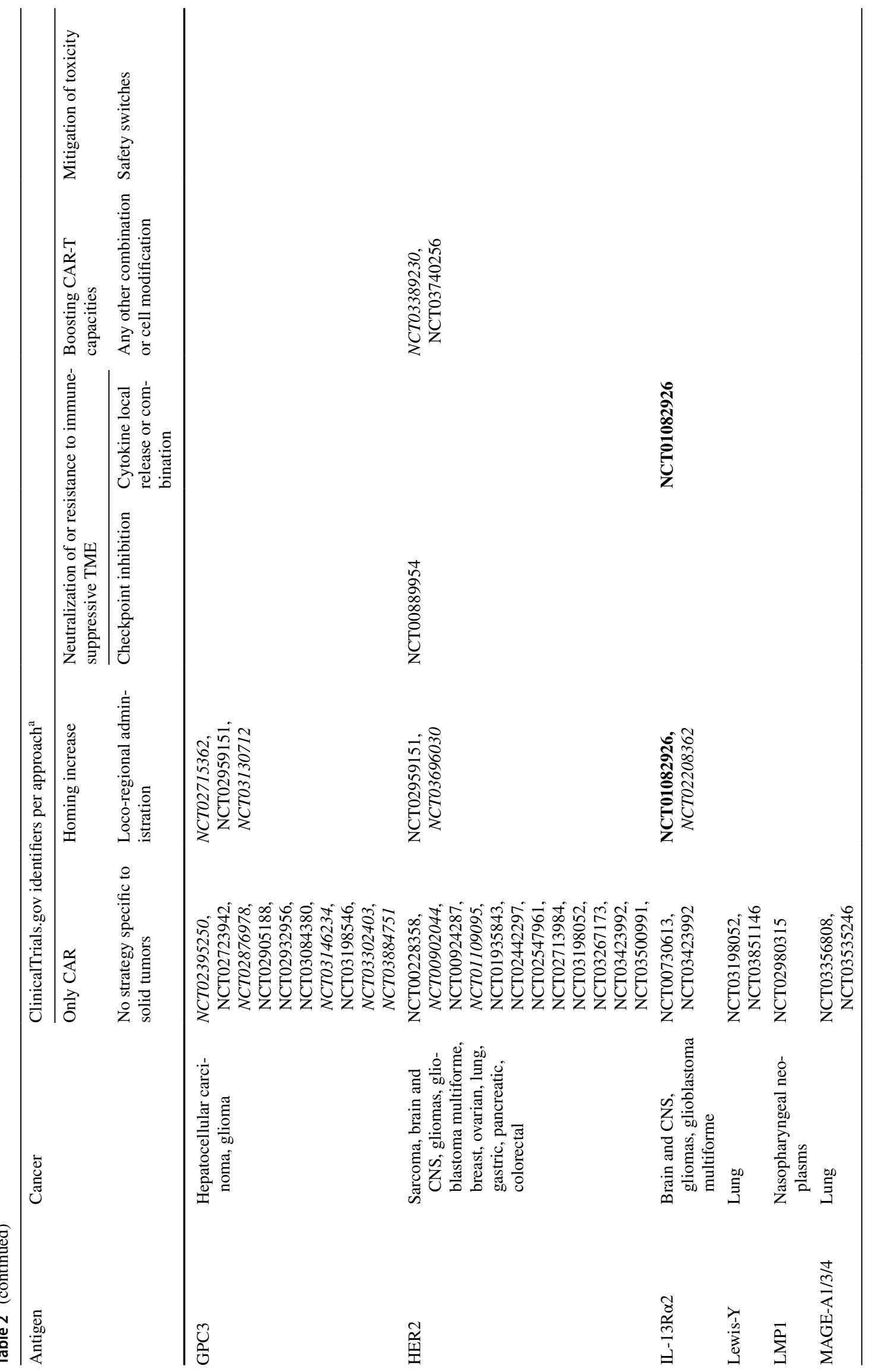




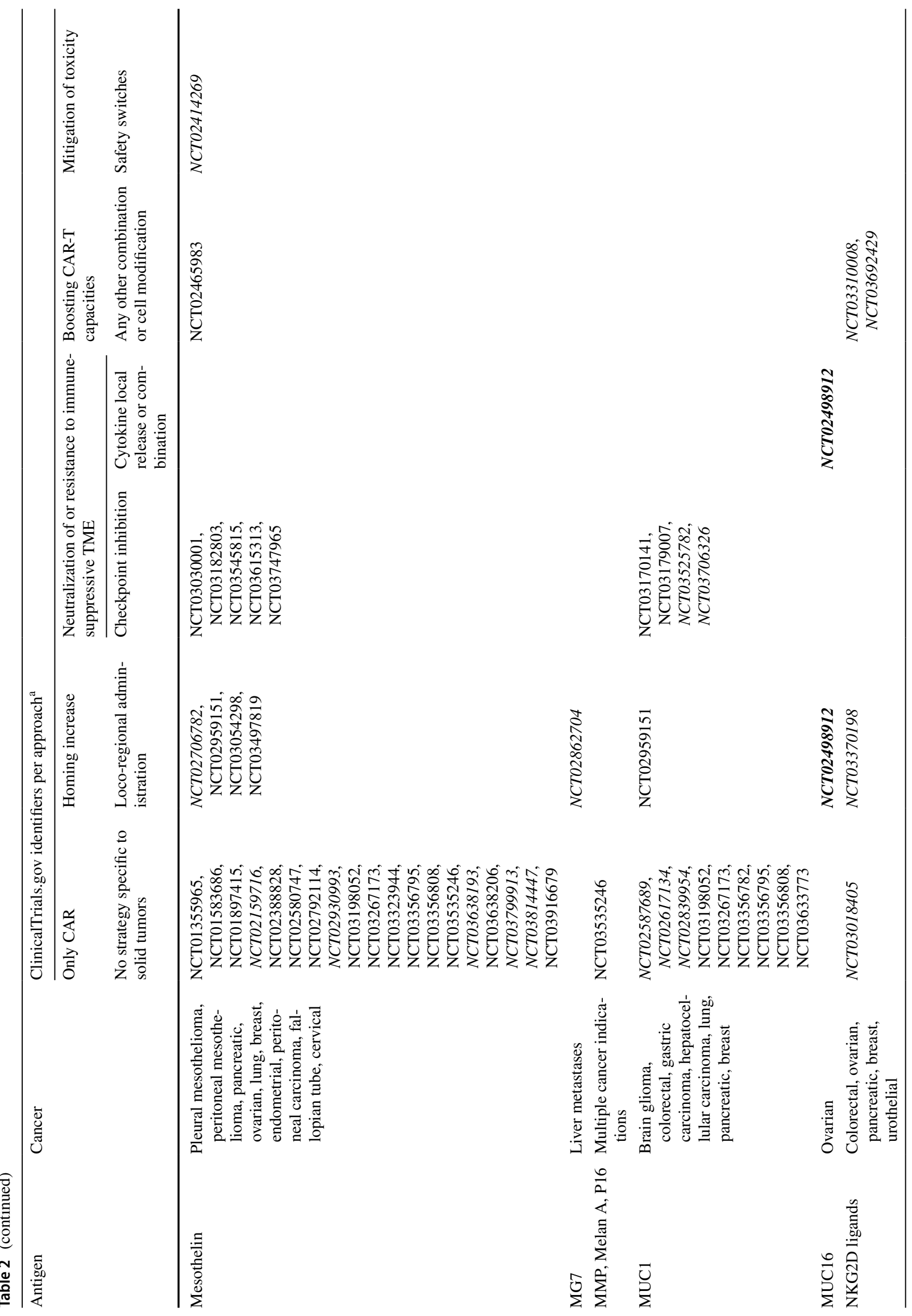




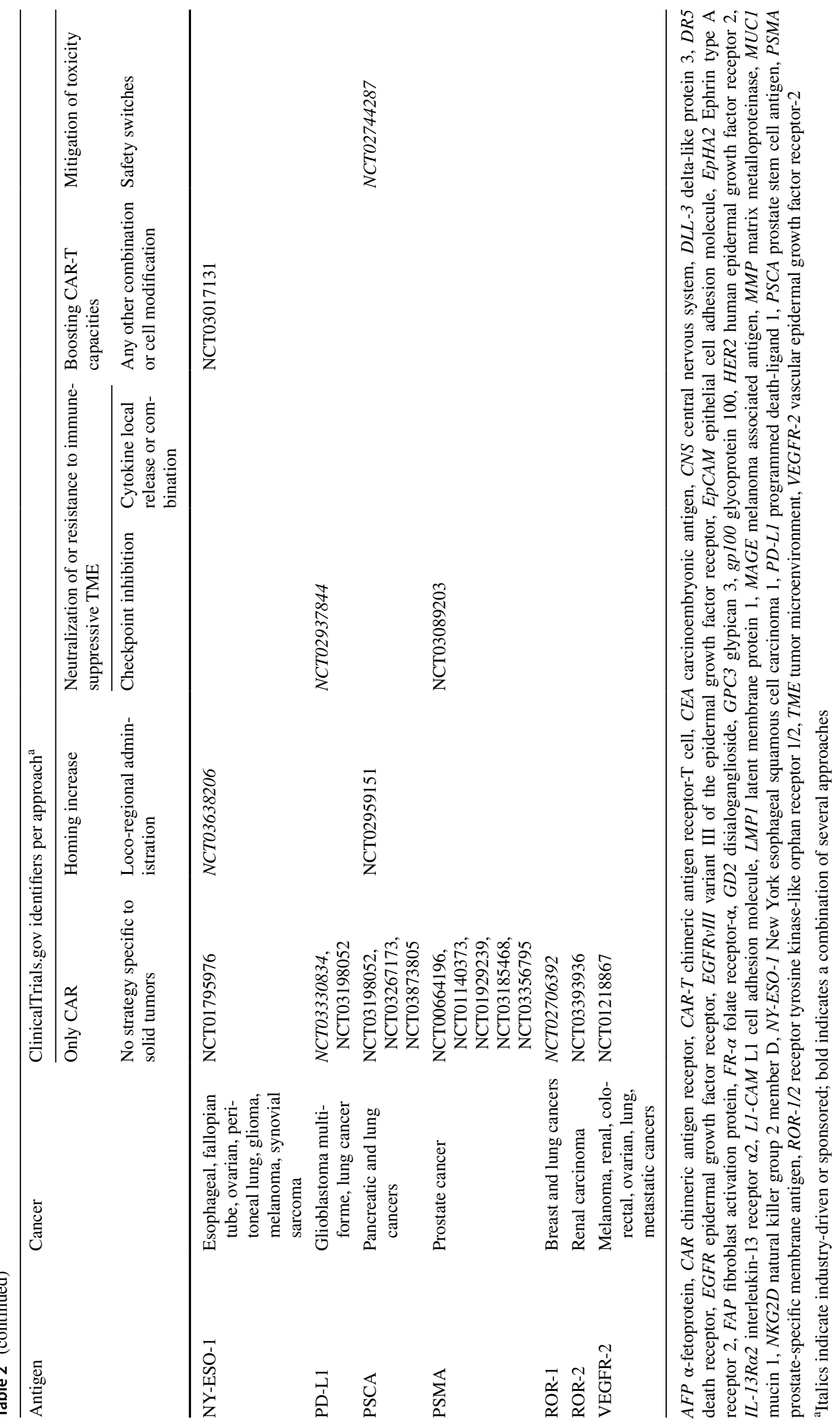




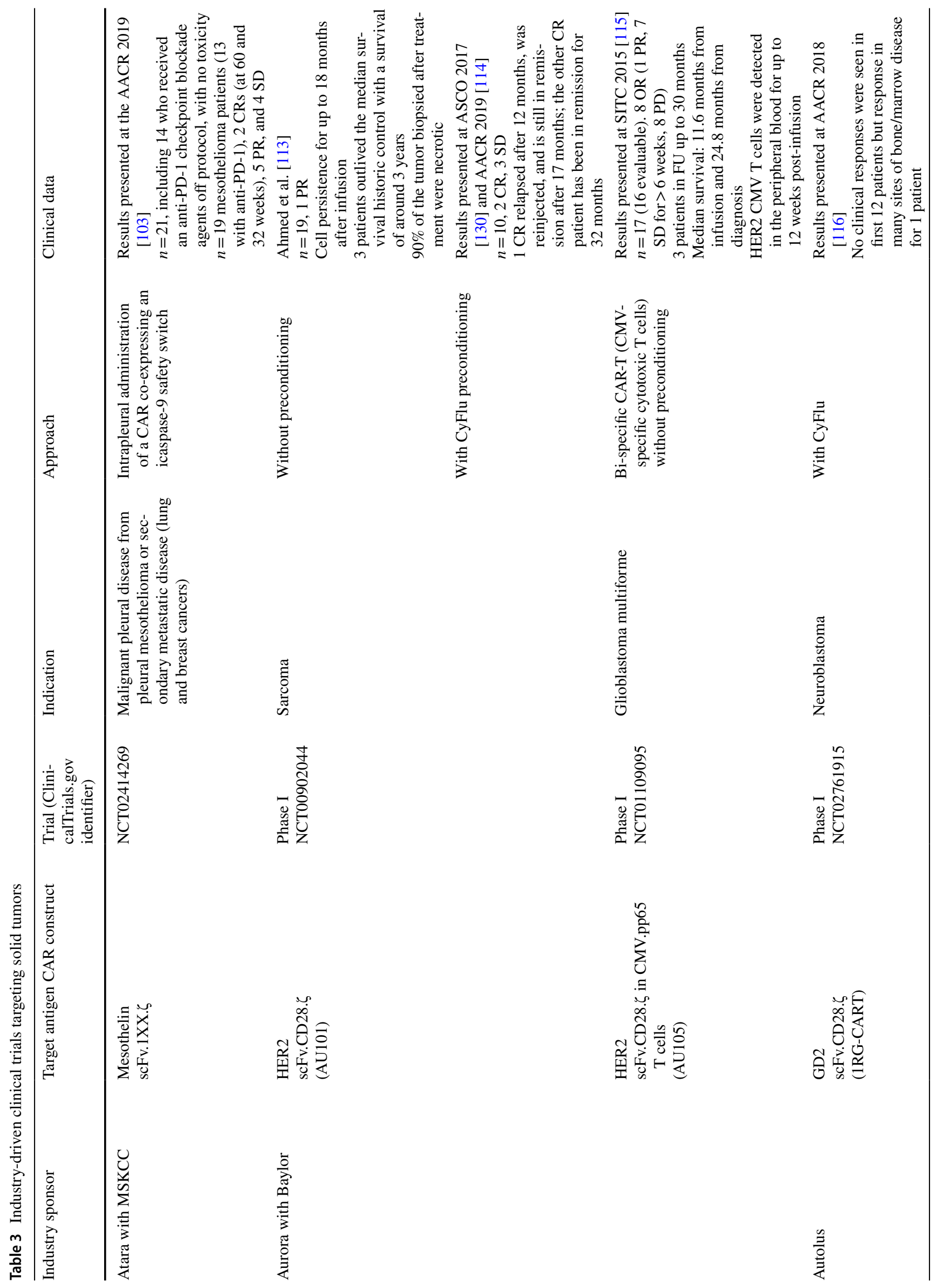




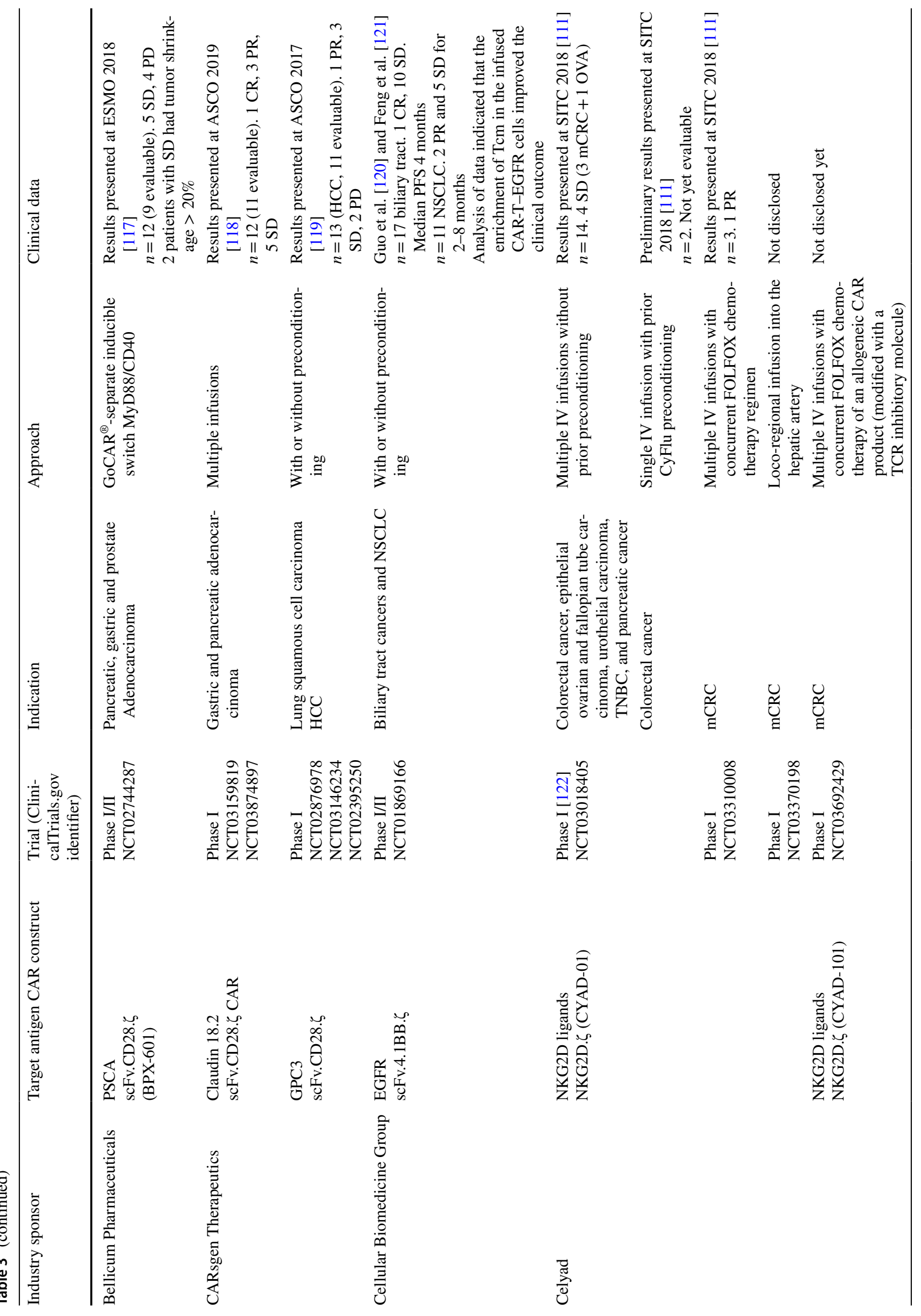




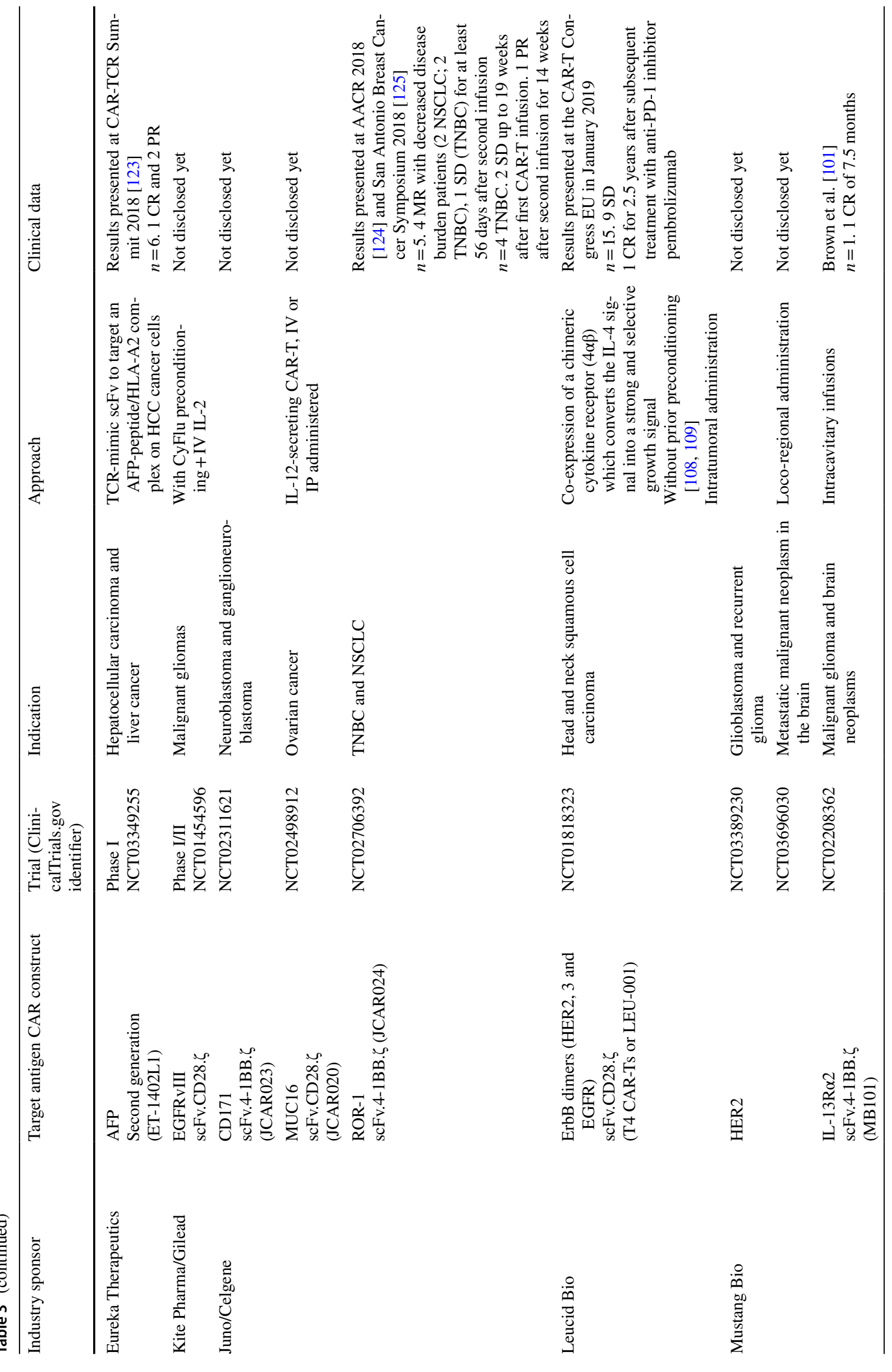




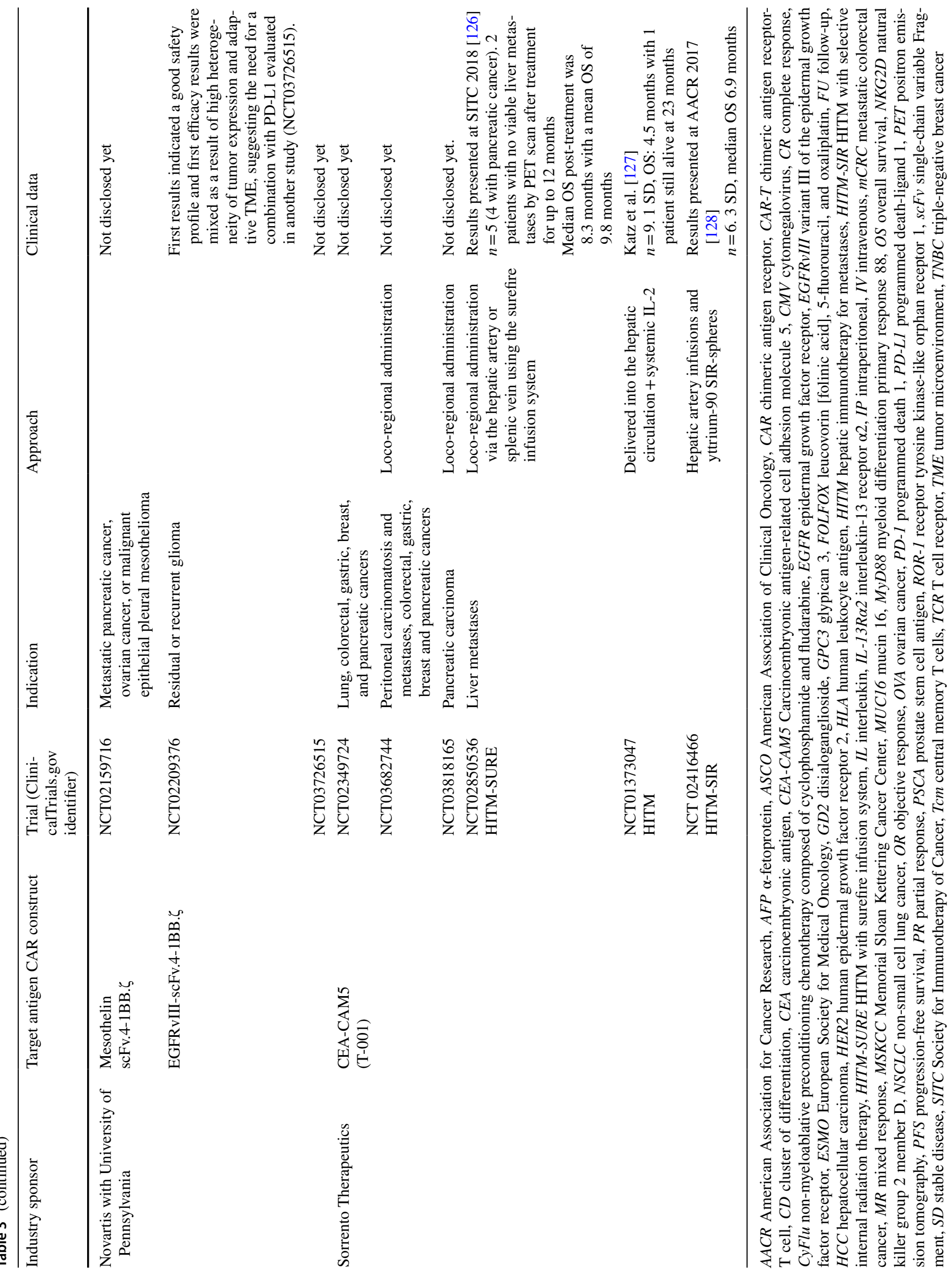


Celyad is also involved in CAR-T development for solid tumors. Based on the broad (eight-ligand) targeting capability of NKG2D CAR-Ts that target cancer cells and also stressed stromal cells within the solid tumor environment (approach detailed in Sect. 2.4), in 2016 Celyad initiated a complete clinical development plan first based on its lead product candidate, CYAD-01 (also known as NKR-2), a 'first-generation' CAR (comprising the full-length human NKG2D receptor fused to the intracellular domain of CD3ל) functioning rather like a second-generation CAR-T thanks to its interaction with the naturally endogenously expressed costimulatory molecule DAP-10 (DNAX-activating protein 10) at the $\mathrm{T}$ cell surface. Three studies evaluating the CYAD-01 product are directed against solid tumor indications [110]. Preliminary data indicated signs of clinical activity following multiple intravenous administrations of CYAD-01 without prior lymphodepletion preconditioning in patients with colorectal cancer or ovarian cancer (four SD over the 14 patients recruited in the solid tumor arm [111]). The second trial is SHRINK (NCT03310008), which is evaluating CYAD-01 administered concurrently to a standard neoadjuvant FOLFOX (leucovorin [folinic acid], 5-fluorouracil, and oxaliplatin) chemotherapy regimen in metastatic colorectal cancer (mCRC) with the aim of improving CYAD-01 engraftment in addition to the TME remodeling induced by the chemotherapy (approach detailed in Sect. 2.2). Preliminary data presented at SITC (Society for Immunotherapy of Cancer) 2018 indicated encouraging signs of activity with a partial response observed in one of three patients [111]. The LINK study (NCT03370198) focuses on loco-regional infusion into the hepatic artery of the CYAD-01 cells in patients with mCRC (approach detailed in Sect. 2.1).

Importantly, Celyad also developed an allogeneic analog of CYAD-01, using a TCR inhibitor molecule (TIM) coded within the vector construct to control the risk of GvHD, called CYAD-101, which is currently being evaluated in a phase I study with a similar study design as the SHRINK study - the alloSHRINK study (NCT03692429). At this time, this is the only clinical trial with an allogeneic CAR-T in a solid tumor, while there are still very limited allogeneic programs specifically designed for solid tumors in preclinical development (approach detailed in Sect. 2.6).

\section{Methodology}

For the pie charts in Figs. 1 and 2, a list of clinical trials evaluating CAR-T therapies was compiled from the ClinicalTrials.gov registry and the number of trials targeting specific organ classes or using a specific approach was counted for each represented option. Only for the pie chart representing the target antigens used in trials targeting solid tumors (Fig. 2; left chart), the numbers represented consider all trials evaluating that specific target antigen, i.e., where a trial is evaluating several targets in parallel, it is counted individually for each target (as detailed in Table 2).

\section{Conclusions}

CAR-T therapy for the treatment of solid tumors is currently being evaluated in approximately one-third of the clinical trials of CAR-T approaches, with several companies now moving into the area (Table 3). While the number of patients with solid tumors dramatically outnumber those with hematological malignancies (Fig. 1), CAR-T therapies targeting solid cancers have yet to demonstrate the clinical activity achieved with hematological indications [112].

Considerable efforts have been made in recent years to develop new approaches to overcome the hurdles raised by solid tumors and optimize the CAR-T therapy for these specific indications, including strategies to increase the tumor accessibility and infiltration of CAR-Ts within the tumor site, neutralize and/or modulate the immunosuppressive TME, improve the CAR-T functions, and/or mitigate potential toxicities.

Finally, apart from those strategies to make CAR-Ts work in solid tumors, there will also be the need to make those technologies more affordable for their clinical usage to become widespread. By using healthy donor cells instead of each patient's cells, allogeneic CAR-T could be one way of reaching this goal.

Still, to date, despite a few interesting results, there is little evidence that CAR-T therapy can advance as a standard treatment option for patients with solid tumors. Therefore, a key question is whether the current CAR-T structure utilizing one of the strategies discussed here is able, for example, to circumvent all of the mentioned hurdles, or whether those CAR-Ts will require additional fundamental changes in their architecture to eventually be sufficiently active against solid tumors.

\section{Compliance with Ethical Standards}

Funding No external funding was used in the preparation of this review.

Conflict of interest Lorraine Springuel, Caroline Lonez, Bertrand Alexandre, David E. Gilham, Anne Flament, and Frédéric F. Lehmann are employees of Celyad SA. Mateusz Opyrchal has consulting agreements with Novartis and AstraZeneca, and has received research funding from Pfizer and Bayer. Eric Van Cutsem reports participation in advisory boards for AstraZeneca, Bayer, Bristol-Myers Squibb, Celgene, Lilly, Merck Sharp \& Dohme, Merck KGaA, Novartis, Roche, and Servier and research grants from Amgen, Bayer, Boehringer Ingelheim, Celgene, Ipsen, Lilly, Roche, Merck Sharp \& Dohme, Merck $\mathrm{KGaA}$, Novartis, Roche, and Servier paid to his institution (Cliniques Universitaires Saint-Luc) outside the submitted work. Jean-Pascal H. 
Machiels, Marc Van Den Eynde, Hans Prenen, Alain Hendlisz, Eric Van Cutsem, Leila Shaza, Javier Carrasco, Jean-Luc Canon, Mateusz Opyrchal, Kunle Odunsi, and Sylvie Rottey are investigators on Celyad's sponsored trials.

Open Access This article is distributed under the terms of the Creative Commons Attribution-NonCommercial 4.0 International License (http://creativecommons.org/licenses/by-nc/4.0/), which permits any noncommercial use, distribution, and reproduction in any medium, provided you give appropriate credit to the original author(s) and the source, provide a link to the Creative Commons license, and indicate if changes were made.

\section{References}

1. Gross G, Waks T, Eshhar Z. Expression of immunoglobulin-T-cell receptor chimeric molecules as functional receptors with antibody-type specificity. Proc Natl Acad Sci USA. 1989;86:10024-8.

2. Sadelain M, Brentjens R, Riviere I. The basic principles of chimeric antigen receptor (CAR) design. Cancer Discov. 2013;3:388-98.

3. Leick MB, Maus MV. CAR-T cells beyond CD19, UnCAR-Ted territory. Am J Hematol. 2019;94:S34-41.

4. Havard R, Stephens DM. Anti-CD19 chimeric antigen receptor $\mathrm{T}$ cell therapies: harnessing the power of the immune system to fight diffuse large B cell lymphoma. Curr Hematol Malig Rep. 2018;13:534-42.

5. Brentjens R, Davila ML, Riviere I, Park J, Wang X, Cowell LG, et al. CD19-targeted $\mathrm{T}$ cells rapidly induce molecular remissions in adults with chemotherapy-refractory acute lymphoblastic leukemia. Sci Transl Med. 2013;5:177ra38.

6. Davila ML, Riviere I, Wang X, Bartido S, Park J, Curran K, et al. Efficacy and toxicity management of 19-28z CAR T cell therapy in B cell acute lymphoblastic leukemia. Sci Transl Med. 2014;6:224ra25.

7. Kochenderfer JN, Dudley ME, Kassim SH, Somerville RPT, Carpenter RO, Stetler-Stevenson M, et al. Chemotherapyrefractory diffuse large B-cell lymphoma and indolent B-cell malignancies can be effectively treated with autologous $\mathrm{T}$ cells expressing an anti-CD19 chimeric antigen receptor. J Clin Oncol. 2015;33:540-9.

8. Maude SL, Frey N, Shaw PA, Aplenc R, Barrett DM, Bunin NJ, et al. Chimeric antigen receptor $\mathrm{T}$ cells for sustained remissions in leukemia. N Engl J Med. 2014;371:1507-17.

9. European Medicines Agency. Yescarta. 2018. https://www.ema. europa.eu/en/medicines/human/EPAR/yescarta. Accessed $25 \mathrm{Apr}$ 2019.

10. U.S. Food and Drug Administration. Approved products-YESCARTA (axicabtagene ciloleucel). https://www.fda.gov/biolo gicsbloodvaccines/cellulargenetherapyproducts/approvedproduct s/ucm581222.htm. Accessed 25 Apr 2019.

11. European Medicines Agency. Kymriah. 2018. https://www.ema. europa.eu/en/medicines/human/EPAR/kymriah. Accessed 25 Apr 2019

12. U.S. Food and Drug Administration. Approved Products-KYMRIAH (tisagenlecleucel). https://www.fda.gov/biologicsbloodv accines/cellulargenetherapyproducts/approvedproducts/ucm57 3706.htm. Accessed 25 Apr 2019.

13. Maude SL, Laetsch TW, Buechner J, Rives S, Boyer M, Bittencourt $\mathrm{H}$, et al. Tisagenlecleucel in children and young adults with B-cell lymphoblastic leukemia. N Engl J Med. 2018;378:439-48.
14. Neelapu SS, Locke FL, Bartlett NL, Lekakis LJ, Miklos DB, Jacobson CA, et al. Axicabtagene ciloleucel CAR T-cell therapy in refractory large B-cell lymphoma. N Engl J Med. 2017;377:2531-44.

15. Anderson KG, Stromnes IM, Greenberg PD. Obstacles posed by the tumor microenvironment to T cell activity: a case for synergistic therapies. Cancer Cell. 2017;31:311-25.

16. Beatty GL, Moon EK. Chimeric antigen receptor T cells are vulnerable to immunosuppressive mechanisms present within the tumor microenvironment. OncoImmunology. 2014;3:e970027.

17. Moon EK, Wang L-C, Dolfi DV, Wilson CB, Ranganathan R, Sun $\mathrm{J}$, et al. Multifactorial T-cell hypofunction that is reversible can limit the efficacy of chimeric antigen receptor-transduced human T cells in solid tumors. Clin Cancer Res. 2014;20:4262-73.

18. Ramamonjisoa N, Ackerstaff E. Characterization of the tumor microenvironment and tumor-stroma interaction by non-invasive preclinical imaging. Front Oncol. 2017;7:3.

19. Jensen MC, Riddell SR. Designing chimeric antigen receptors to effectively and safely target tumors. Curr Opin Immunol. 2015;33:9-15.

20. Sackstein R. The first step in adoptive cell immunotherapeutics: assuring cell delivery via glycoengineering. Front Immunol. 2019;9:3084.

21. Di Stasi A, De Angelis B, Rooney CM, Zhang L, Mahendravada A, Foster AE, et al. T lymphocytes coexpressing CCR21 and a chimeric antigen receptor targeting CD30 have improved homing and antitumor activity in a Hodgkin tumor model. Blood. 2009;113:6392-402.

22. Craddock JA, Lu A, Bear A, Pule M, Brenner MK, Rooney CM, et al. Enhanced tumor trafficking of GD2 chimeric antigen receptor $\mathrm{T}$ cells by expression of the chemokine receptor CCR22b. J Immunother. 2010;33:780-8.

23. Tokarew N, Ogonek J, Endres S, von Bergwelt-Baildon M, Kobold S. Teaching an old dog new tricks: next-generation CAR T cells. Br J Cancer. 2019;120:26-37.

24. Sridhar P, Petrocca F. Regional delivery of chimeric antigen receptor (CAR) T-cells for cancer therapy. Cancers (Basel). 2017;9(7):92.

25. Parente-Pereira AC, Burnet J, Ellison D, Foster J, Davies DM, van der Stegen $\mathrm{S}$, et al. Trafficking of CAR-engineered human $\mathrm{T}$ cells following regional or systemic adoptive transfer in SCID beige mice. J Clin Immunol. 2011;31:710-8.

26. Katz S, Point GR, Cunetta M, Thorn M, Guha P, Espat NJ, et al. Regional CAR-T cell infusions for peritoneal carcinomatosis are superior to systemic delivery. Cancer Gene Ther. 2016;23:142-8.

27. Adusumilli PS, Cherkassky L, Villena-Vargas J, Colovos C, Servais E, Plotkin J, et al. Regional delivery of mesothelin-targeted CAR T cell therapy generates potent and long-lasting CD4dependent tumor immunity. Sci Transl Med. 2014;6:261ra151.

28. Smith TT, Stephan SB, Moffett HF, McKnight LE, Ji W, Reiman $\mathrm{D}$, et al. In situ programming of leukaemia-specific T cells using synthetic DNA nanocarriers. Nat Nanotechnol. 2017;12:813-20.

29. Topalian SL, Taube JM, Anders RA, Pardoll DM. Mechanismdriven biomarkers to guide immune checkpoint blockade in cancer therapy. Nat Rev Cancer. 2016;16:275-87.

30. John LB, Devaud C, Duong CPM, Yong CS, Beavis PA, Haynes $\mathrm{NM}$, et al. Anti-PD-1 antibody therapy potently enhances the eradication of established tumors by gene-modified $\mathrm{T}$ cells. Clin Cancer Res. 2013;19:5636-46.

31. Wang L, Yao R, Zhang L, Fan C, Ma L, Liu J. Chimeric antigen receptor $\mathrm{T}$ cell therapy and other therapeutics for malignancies: combination and opportunity. Int Immunopharmacol. 2019;70:498-503.

32. Cherkassky L, Morello A, Villena-Vargas J, Feng Y, Dimitrov DS, Jones DR, et al. Human CAR T cells with cell-intrinsic 
PD-1 checkpoint blockade resist tumor-mediated inhibition. J Clin Investig. 2016;126:3130-44.

33. Kloss CC, Lee J, Zhang A, Chen F, Melenhorst JJ, Lacey SF, et al. Dominant-negative TGF- $\beta$ receptor enhances PSMA-targeted human CAR T cell proliferation and augments prostate cancer eradication. Mol Ther. 2018;26:1855-66.

34. Yamamoto TN, Lee P-H, Vodnala SK, Gurusamy D, Kishton $\mathrm{RJ}, \mathrm{Yu} \mathrm{Z}$, et al. T cells genetically engineered to overcome death signaling enhance adoptive cancer immunotherapy. J Clin Invest. 2019;129(4):1551-65.

35. Rupp LJ, Schumann K, Roybal KT, Gate RE, Ye CJ, Lim WA, et al. CRISPR/Cas9-mediated PD-1 disruption enhances antitumor efficacy of human chimeric antigen receptor T cells. Sci Rep. 2017;7:737.

36. Rafiq S, Yeku OO, Jackson HJ, Purdon TJ, van Leeuwen DG, Drakes DJ, et al. Targeted delivery of a PD-1-blocking scFv by CAR-T cells enhances anti-tumor efficacy in vivo. Nat Biotechnol. 2018;36:847-56.

37. Leen AM, Sukumaran S, Watanabe N, Mohammed S, Keirnan J, Yanagisawa R, et al. Reversal of tumor immune inhibition using a chimeric cytokine receptor. Mol Ther. 2014;22:1211-20.

38. Tang X, Li Q, Zhu Y, Zheng D, Dai J, Ni W, et al. The advantages of PD1 activating chimeric receptor (PD1-ACR) engineered lymphocytes for PDL1+ cancer therapy. Am J Transl Res. 2015;7:460-73.

39. Mohammed S, Sukumaran S, Bajgain P, Watanabe N, Heslop $\mathrm{HE}$, Rooney CM, et al. Improving chimeric antigen receptormodified $\mathrm{T}$ cell function by reversing the immunosuppressive tumor microenvironment of pancreatic cancer. Mol Ther. 2017;25:249-58.

40. Liu X, Ranganathan R, Jiang S, Fang C, Sun J, Kim S, et al. A chimeric switch-receptor targeting PD1 augments the efficacy of second-generation CAR T cells in advanced solid tumors. Cancer Res. 2016;76:1578-90.

41. Chmielewski M, Hombach AA, Abken H. Of CARs and TRUCKs: chimeric antigen receptor (CAR) T cells engineered with an inducible cytokine to modulate the tumor stroma. Immunol Rev. 2014;257:83-90.

42. Hu B, Ren J, Luo Y, Keith B, Young RM, Scholler J, et al. Augmentation of antitumor immunity by human and mouse CAR T cells secreting IL-18. Cell Rep. 2017;20:3025-33.

43. Koneru M, Purdon TJ, Spriggs D, Koneru S, Brentjens RJ. IL-12 secreting tumor-targeted chimeric antigen receptor T cells eradicate ovarian tumors in vivo. Oncoimmunology. 2015;4(3):e994446.

44. Yeku OO, Purdon TJ, Koneru M, Spriggs D, Brentjens RJ. Armored CAR T cells enhance antitumor efficacy and overcome the tumor microenvironment. Sci Rep. 2017;7:10541.

45. Chmielewski M, Abken H. CAR T cells releasing IL-18 convert to T-Bet ${ }^{\text {high }}$ FoxO1 ${ }^{\text {low }}$ effectors that exhibit augmented activity against advanced solid tumors. Cell Rep. 2017;21:3205-19.

46. Knochelmann HM, Smith AS, Dwyer CJ, Wyatt MM, Mehrotra S, Paulos CM. CAR T cells in solid tumors: blueprints for building effective therapies. Front Immunol. 2018;9:1740.

47. Chmielewski M, Kopecky C, Hombach AA, Abken H. IL-12 release by engineered $\mathrm{T}$ cells expressing chimeric antigen receptors can effectively muster an antigen-independent macrophage response on tumor cells that have shut down tumor antigen expression. Cancer Res. 2011;71:5697-706.

48. Leonard JP, Sherman ML, Fisher GL, Buchanan LJ, Larsen G, Atkins MB, et al. Effects of single-dose interleukin-12 exposure on interleukin-12-associated toxicity and interferon- $\gamma$ production. Blood. 1997;90:2541-8.

49. Zhang L, Morgan RA, Beane JD, Zheng Z, Dudley ME, Kas$\operatorname{sim} \mathrm{SH}$, et al. Tumor infiltrating lymphocytes genetically engineered with an inducible gene encoding interleukin-12 for the immunotherapy of metastatic melanoma. Clin Cancer Res. 2015;21:2278-88.

50. Robertson MJ, Kirkwood JM, Logan TF, Koch KM, Kathman S, Kirby LC, et al. A dose-escalation study of recombinant human interleukin-18 using two different schedules of administration in patients with cancer. Clin Cancer Res. 2008;14:3462-9.

51. Siriwon N, Kim YJ, Siegler E, Chen X, Rohrs JA, Liu Y, et al. CAR-T cells surface-engineered with drug-encapsulated nanoparticles can ameliorate intratumoral T-cell hypofunction. Cancer Immunol Res. 2018;6:812-24.

52. Fraietta JA, Lacey SF, Orlando EJ, Pruteanu-Malinici I, Gohil $\mathrm{M}$, Lundh S, et al. Determinants of response and resistance to CD19 chimeric antigen receptor (CAR) T cell therapy of chronic lymphocytic leukemia. Nat Med. 2018;24:563-71.

53. Porter DL, Levine BL, Kalos M, Bagg A, June CH. Chimeric antigen receptor-modified $\mathrm{T}$ cells in chronic lymphoid leukemia. N Engl J Med. 2011;365:725-33.

54. Chang ZL, Chen YY. CARs: Synthetic immunoreceptors for cancer therapy and beyond. Trends Mol Med. 2017;23:430-50.

55. Lorenzo-Herrero S, López-Soto A, Sordo-Bahamonde C, Gonzalez-Rodriguez A, Vitale M, Gonzalez S. NK cell-based immunotherapy in cancer metastasis. Cancers. 2018;11:29.

56. Gattinoni L, Lugli E, Ji Y, Pos Z, Paulos CM, Quigley MF, et al. A human memory T-cell subset with stem cell-like properties. Nat Med. 2011;17:1290-7.

57. Long KB, Young RM, Boesteanu AC, Davis MM, Melenhorst JJ, Lacey SF, et al. CAR T cell therapy of non-hematopoietic malignancies: detours on the road to clinical success. Front Immunol. 2018;9:2740.

58. Ghassemi S, Nunez-Cruz S, O'Connor RS, Fraietta JA, Patel PR, Scholler J, et al. Reducing ex vivo culture improves the antileukemic activity of chimeric antigen receptor (CAR) T Cells. Cancer Immunol Res. 2018;6:1100-9.

59. Zheng W, Jones LL, Geiger TL. Modulation of PI3K signaling to improve CAR T cell function. Oncotarget. 2018;9:35807-8.

60. Shah N, Alsina M, Siegel DS, Jagannath S, Madduri D, Kaufman JL, Turka A, Lam LP, Massaro M, Hege K, Petrocca F, Berdeja JG, Raje N. Initial results from a phase 1 clinical study of bb21217, a next-generation Anti Bcma CAR T therapy. Blood 2018; 132:488. https://doi.org/10.1182/blood-2018-99-116953

61. Cieri N, Camisa B, Cocchiarella F, Forcato M, Oliveira G, Provasi E, et al. IL-7 and IL-15 instruct the generation of human memory stem $\mathrm{T}$ cells from naive precursors. Blood. 2013;121:573-84.

62. Xu Y, Zhang M, Ramos CA, Durett A, Liu E, Dakhova O, et al. Closely related T-memory stem cells correlate with in vivo expansion of CAR.CD19-T cells and are preserved by IL-7 and IL-15. Blood. 2014;123:3750-9.

63. Künkele A, Johnson AJ, Rolczynski LS, Chang CA, Hoglund V, Kelly-Spratt KS, et al. Functional tuning of CARs reveals signaling threshold above which CD8+ CTL antitumor potency is attenuated due to cell Fas-FasL-dependent AICD. Cancer Immunol Res. 2015;3:368-79.

64. Zhao Z, Condomines M, van der Stegen SJC, Perna F, Kloss CC, Gunset G, et al. Structural design of engineered costimulation determines tumor rejection kinetics and persistence of CAR T cells. Cancer Cell. 2015;28:415-28.

65. Feucht J, Sun J, Eyquem J, Ho Y-J, Zhao Z, Leibold J, et al. Calibration of CAR activation potential directs alternative $\mathrm{T}$ cell fates and therapeutic potency. Nat Med. 2019;25:82.

66. Sakemura R, Terakura S, Watanabe K, Julamanee J, Takagi E, Miyao K, et al. A Tet-On inducible system for controlling CD19chimeric antigen receptor expression upon drug administration. Cancer Immunol Res. 2016;4(8):658-68. 
67. Davies DM, Maher J. Gated chimeric antigen receptor T-cells: the next logical step in reducing toxicity? Transl Cancer Res. 2016;5:S61-5.

68. Kloss CC, Condomines M, Cartellieri M, Bachmann M, Sadelain $\mathrm{M}$. Combinatorial antigen recognition with balanced signaling promotes selective tumor eradication by engineered $\mathrm{T}$ cells. Nat Biotechnol. 2013;31:71-5.

69. Lanitis E, Poussin M, Klattenhoff AW, Song D, Sandaltzopoulos $\mathrm{R}$, June $\mathrm{CH}$, et al. Chimeric antigen receptor $\mathrm{T}$ cells with dissociated signaling domains exhibit focused anti-tumor activity with reduced potential for toxicity in vivo. Cancer Immunol Res. 2013;1:43-53.

70. Fedorov VD, Themeli M, Sadelain M. PD-1- and CTLA-4-based inhibitory chimeric antigen receptors (iCARs) divert off-target immunotherapy responses. Sci Transl Med. 2013;5:215ra172.

71. Barber A, Rynda A, Sentman CL. Chimeric NKG2D expressing $\mathrm{T}$ cells eliminate immunosuppression and activate immunity within the ovarian tumor microenvironment. J Immunol. 2009;183:6939-47.

72. Demoulin B, Cook WJ, Murad J, Graber DJ, Sentman M-L, Lonez C, et al. Exploiting natural killer group 2D receptors for CAR T-cell therapy. Future Oncol. 2017;13(18):1593-605.

73. Zhang T, Sentman CL. Mouse tumor vasculature expresses NKG2D ligands and can be targeted by chimeric NKG2D-modified T cells. J Immunol. 2013;190:2455-63.

74. Whilding LM, Maher J. ErbB-targeted CAR T-cell immunotherapy of cancer. Immunotherapy. 2015;7:229-41.

75. Gilham DE, Maher J. 'Atypical' CAR T cells: NKG2D and Erb-B as examples of natural receptor/ligands to target recalcitrant solid tumors. Immunotherapy. 2017;9:723-33.

76. Davies DM, Foster J, van der Stegen SJ, Parente-Pereira AC, Chiapero-Stanke L, Delinassios GJ, et al. Flexible targeting of ErbB dimers that drive tumorigenesis by using genetically engineered T cells. Mol Med. 2012;18:565.

77. Klampatsa A, Achkova DY, Davies DM, Parente-Pereira AC, Woodman N, Rosekilly J, et al. Intracavitary "T4 immunotherapy" of malignant mesothelioma using pan-ErbB re-targeted CAR T-cells. Cancer Lett. 2017;393:52-9.

78. Labanieh L, Majzner RG, Mackall CL. Programming CAR-T cells to kill cancer. Nat Biomed Eng. 2018;2:377-91.

79. Xie YJ, Dougan M, Jailkhani N, Ingram J, Fang T, Kummer L, et al. Nanobody-based CAR T cells that target the tumor microenvironment inhibit the growth of solid tumors in immunocompetent mice. Proc Natl Acad Sci. 2019;116:7624-31.

80. Beatty GL, Haas AR, Maus MV, Torigian DA, Soulen MC, Plesa $\mathrm{G}$, et al. Mesothelin-specific chimeric antigen receptor mRNAengineered $\mathrm{T}$ cells induce antitumor activity in solid malignancies. Cancer Immunol Res. 2014;2:112-20.

81. Deniger DC, Yu J, Huls MH, Figliola MJ, Mi T, Maiti SN, et al. Sleeping beauty transposition of chimeric antigen receptors targeting receptor tyrosine kinase-like orphan receptor-1 (ROR1) into diverse memory T-cell populations. PLOS One. 2015;10:e0128151.

82. Wang L-CS, Lo A, Scholler J, Sun J, Majumdar RS, Kapoor V, et al. Targeting fibroblast activation protein in tumor stroma with chimeric antigen receptor $\mathrm{T}$ cells can inhibit tumor growth and augment host immunity without severe toxicity. Cancer Immunol Res. 2014;2:154-66.

83. Stromnes IM, Schmitt TM, Hulbert A, Brockenbrough JS, Nguyen HN, Cuevas C, et al. T Cells engineered against a native antigen can surmount immunologic and physical barriers to treat pancreatic ductal adenocarcinoma. Cancer Cell. 2015;28:638-52.

84. Paszkiewicz PJ, Fräßle SP, Srivastava S, Sommermeyer D, Hudecek M, Drexler I, et al. Targeted antibody-mediated depletion of murine CD19 CAR T cells permanently reverses B cell aplasia. J Clin Investig. 2016;126:4262-72.
85. Philip B, Kokalaki E, Mekkaoui L, Thomas S, Straathof K, Flutter B, et al. A highly compact epitope-based marker/suicide gene for easier and safer T-cell therapy. Blood. 2014;124:1277-87.

86. Straathof KC, Pulè MA, Yotnda P, Dotti G, Vanin EF, Brenner MK, et al. An inducible caspase 9 safety switch for T-cell therapy. Blood. 2005;105:4247-54.

87. Rodgers DT, Mazagova M, Hampton EN, Cao Y, Ramadoss NS, Hardy IR, et al. Switch-mediated activation and retargeting of CAR-T cells for B-cell malignancies. Proc Natl Acad Sci USA. 2016;113:E459-68.

88. Ma JSY, Kim JY, Kazane SA, Choi S, Yun HY, Kim MS, et al. Versatile strategy for controlling the specificity and activity of engineered T cells. Proc Natl Acad Sci USA. 2016;113:E450-8.

89. Cho JH, Collins JJ, Wong WW. Universal chimeric antigen receptors for multiplexed and logical control of T cell responses. Cell. 2018;173:1426.e11-1438.e11.

90. Cartellieri M, Feldmann A, Koristka S, Arndt C, Loff S, Ehninger A, et al. Switching CAR T cells on and off: a novel modular platform for retargeting of T cells to AML blasts. Blood Cancer J. 2016;6:e458.

91. Tamada K, Geng D, Sakoda Y, Bansal N, Srivastava R, Li Z, et al. Redirecting gene-modified $\mathrm{T}$ cells toward various cancer types using tagged antibodies. Clin Cancer Res. 2012;18:6436-45.

92. Urbanska K, Lanitis E, Poussin M, Lynn RC, Gavin BP, Kelderman S, et al. A universal strategy for adoptive immunotherapy of cancer through use of a novel T-cell antigen receptor. Cancer Res. 2012;72:1844-52.

93. Torikai H, Reik A, Liu P-Q, Zhou Y, Zhang L, Maiti S, et al. A foundation for universal T-cell based immunotherapy: $\mathrm{T}$ cells engineered to express a CD19-specific chimeric-antigenreceptor and eliminate expression of endogenous TCR. Blood. 2012;119:5697-705.

94. Torikai H, Reik A, Soldner F, Warren EH, Yuen C, Zhou Y, et al. Toward eliminating HLA class I expression to generate universal cells from allogeneic donors. Blood. 2013;122:1341-9.

95. Siolas D, Hannon GJ. Patient derived tumor xenografts: transforming clinical samples into mouse models. Cancer Res. 2013;73:5315-9.

96. Yada E, Wada S, Yoshida S, Sasada T. Use of patient-derived xenograft mouse models in cancer research and treatment. Future Sci OA. 2018;4(3):FSO271.

97. Lamers CHJ, Willemsen R, van Elzakker P, van SteenbergenLangeveld S, Broertjes M, Oosterwijk-Wakka J, et al. Immune responses to transgene and retroviral vector in patients treated with ex vivo-engineered T cells. Blood. 2011;117:72-82.

98. Lamers CHJ, Langeveld SCL, Groot-van Ruijven CM, Debets R, Sleijfer S, Gratama JW. Gene-modified T cells for adoptive immunotherapy of renal cell cancer maintain transgene-specific immune functions in vivo. Cancer Immunol Immunother. 2007;56:1875-83.

99. Morgan RA, Yang JC, Kitano M, Dudley ME, Laurencot CM, Rosenberg SA. Case report of a serious adverse event following the administration of $\mathrm{T}$ cells transduced with a chimeric antigen receptor recognizing ERBB2. Mol Ther. 2010;18:843-51.

100. Brown CE, Badie B, Barish ME, Weng L, Ostberg JR, Chang W-C, et al. Bioactivity and safety of IL13R $\alpha 2$-redirected chimeric antigen receptor $\mathrm{CD} 8+\mathrm{T}$ cells in patients with recurrent glioblastoma. Clin Cancer Res. 2015;21:4062-72.

101. Brown CE, Alizadeh D, Starr R, Weng L, Wagner JR, Naranjo A, et al. Regression of glioblastoma after chimeric antigen receptor T-cell therapy. N Engl J Med. 2016;375:2561-9.

102. Ahmed N, Brawley V, Hegde M, Bielamowicz K, Kalra M, Landi D, et al. HER2-specific chimeric antigen receptor-modified virus-specific $\mathrm{T}$ cells for progressive glioblastoma: a phase 1 dose-escalation trial. JAMA Oncol. 2017;3(8):1094-101.

103. Adusumilli PS, Zauderer MG, Rusch V, O’Cearbhaill RE, Zhu A, Ngai D, et al. A phase I clinical trial of malignant pleural disease 
treated with regionally delivered autologous mesothelin-targeted CAR T cells: safety and efficacy [abstract no. CT036]. AACR annual meeting, Atlanta; 2019. https://www.abstractsonline.com/ pp8/\#!/6812/presentation/9837. Accessed 3 May 2019.

104. Becerra CR, Hoof P, Paulson AS, Manji GA, Gardner O, Malankar A, et al. Ligand-inducible, prostate stem cell antigen (PSCA)-directed GoCAR-T cells in advanced solid tumors: preliminary results from a dose escalation [abstract no. 283]. J Clin Oncol. 2019;37(4 Suppl):283. https://ascopubs.org/doi/ abs/10.1200/JCO.2019.37.4_suppl.283. Accessed 16 May 2019.

105. Park JR, Digiusto DL, Slovak M, Wright C, Naranjo A, Wagner $\mathrm{J}$, et al. Adoptive transfer of chimeric antigen receptor re-directed cytolytic T lymphocyte clones in patients with neuroblastoma. Mol Ther J Am Soc Gene Ther. 2007;15:825-33.

106. Pule MA, Savoldo B, Myers GD, Rossig C, Russell HV, Dotti $\mathrm{G}$, et al. Virus-specific T cells engineered to coexpress tumorspecific receptors: persistence and antitumor activity in individuals with neuroblastoma. Nat Med. 2008;14:1264-70.

107. Louis CU, Savoldo B, Dotti G, Pule M, Yvon E, Myers GD, et al. Antitumor activity and long-term fate of chimeric antigen receptor-positive $\mathrm{T}$ cells in patients with neuroblastoma. Blood. 2011;118:6050-6.

108. van Schalkwyk MCI, Papa SE, Jeannon J-P, Urbano TG, Spicer JF, Maher J. Design of a phase I clinical trial to evaluate intratumoral delivery of ErbB-targeted chimeric antigen receptor T-cells in locally advanced or recurrent head and neck cancer. Hum Gene Ther Clin Dev. 2013;24:134-42.

109. Papa S, van Schalkwyk M, Maher J. Clinical evaluation of ErbBtargeted CAR T-cells, following intracavity delivery in patients with ErbB-expressing solid tumors. In: Walther W, Stein U, editors. Gene therapy of solid cancers. New York: Springer; 2015. pp. 365-82. http://link.springer.com/10.1007/978-1-4939-27272_21. Accessed 16 Mar 2016.

110. Lonez C, Hendlisz A, Shaza L, Aftimos P, Vouche M, Donckier $\mathrm{V}$, et al. Celyad's novel CAR T-cell therapy for solid malignancies. Curr Res Transl Med. 2018;66:53-6.

111. Hendlisz A. Results and perspectives from phase 1 studies assessing the safety and clinical activity of multiple doses of a NKG2D-based CAR-T therapy, CYAD-01, in metastatic solid tumors [abstract no. P255]. Society of Immunotherapy Cancer (SITC) 2018; 7-11 Nov 2018; Washington, DC.

112. Hou B, Tang Y, Li W, Zeng Q, Chang D. Efficiency of CAR-T therapy for treatment of solid tumor in clinical trials: a metaanalysis. Dis Markers. 2019;2019:3425291.

113. Ahmed N, Brawley VS, Hegde M, Robertson C, Ghazi A, Gerken C, et al. Human epidermal growth factor receptor 2 (HER2)-specific chimeric antigen receptor-modified T cells for the immunotherapy of HER2-positive sarcoma. J Clin Oncol. 2015;33:1688-96.

114. Navai SA, DeRenzo C, Joseph SK, Sanber K, Byrd T, Zhang $\mathrm{H}$, et al. Administration of HER2-CAR T cells after lymphodepletion safely improves $\mathrm{T}$ cell expansion and induces clinical responses in patients with advanced sarcomas [abstract no. LB-147/4]. 2019. https://www.abstractsonline.com/pp8/\#!/6812/ presentation/9413. Accessed 3 May 2019.

115. Ahmed N, Brawley V, Hegde M, Bielamowicz K, Wakefield A, Ghazi A, et al. Autologous HER2 CMV bispecific CAR T cells are safe and demonstrate clinical benefit for glioblastoma in a phase I trial. J Immunother Cancer. 2015;3:O11.

116. Straathof K, Flutter B, Wallace R, Thomas S, Cheung G, Collura A, et al. A Cancer Research UK phase I trial of anti-GD2 chimeric antigen receptor (CAR) transduced T-cells (1RG-CART) in patients with relapsed or refractory neuroblastoma. Cancer Res. 2018;78:CT145.

117. Bellicum. Ligand-inducible, prostate stem cell antigen (PSCA)directed GoCAR-T ${ }^{\circledR}$ cells in advanced solid tumors: preliminary results from a dose escalation study [abstract no. 320]. ESMO 2018. http://www.bellicum.com/wp-content/uploads/2018/12/ ESMO-IO-2018_Becerra-et-al_Abstract-320_Final-Presentati on.pdf. Accessed 27 Jul 2019.

118. Zhan X, Wang B, Li Z, Li J, Wang H, Chen L, et al. Phase I trial of Claudin 18.2-specific chimeric antigen receptor $\mathrm{T}$ cells for advanced gastric and pancreatic adenocarcinoma [abstract no. 2509]. ASCO 2019 annual meeting. https://meetinglibrary.asco. org/record/172418/abstract. Accessed 17 May 2019.

119. Zhai B, Shi D, Gao H, Qi X, Jiang H, Zhang Y, et al. A phase I study of anti-GPC3 chimeric antigen receptor modified T cells (GPC3 CAR-T) in Chinese patients with refractory or relapsed GPC3+ hepatocellular carcinoma ( $\mathrm{r} / \mathrm{r}$ GPC3 + HCC) [abstract no. 3049]. J Clin Oncol. 2017;35:3049.

120. Guo Y, Feng K, Liu Y, Wu Z, Dai H, Yang Q, et al. Phase I study of chimeric antigen receptor modified $T$ cells in patients with EGFR-positive advanced biliary tract cancers. Clin Cancer Res. 2018;24(6):1277-86.

121. Feng K, Guo Y, Dai H, Wang Y, Li X, Jia H, et al. Chimeric antigen receptor-modified $\mathrm{T}$ cells for the immunotherapy of patients with EGFR-expressing advanced relapsed/refractory non-small cell lung cancer. Sci China Life Sci. 2016;59(5):468-79. https:// doi.org/10.1007/s11427-016-5023-8.

122. Lonez C, Verma B, Hendlisz A, Aftimos P, Awada A, Van Den Neste E, et al. Study protocol for THINK: a multinational openlabel phase I study to assess the safety and clinical activity of multiple administrations of NKR-2 in patients with different metastatic tumour types. BMJ Open. 2017;7:e017075.

123. Eureka Therapeutics. Eureka Therapeutics achieves regression of metastatic liver cancer using ET140202 T-cell therapy. https ://www.eurekatherapeutics.com/media/press-releases/090518/. Accessed 22 Mar 2019.

124. Specht JM, Lee S, Turtle CJ, Berger C, Baladrishnan A, Srivastava $\mathrm{S}$, et al. A phase I study of adoptive immunotherapy for advanced ROR1+ malignancies with defined subsets of autologous $\mathrm{T}$ cells expressing a ROR1-specific chimeric antigen receptor (ROR1-CAR). Cancer Res. 2018;78:CT131.

125. Specht JM, et al. A phase I study of adoptive immunotherapy for ROR1+ advanced triple negative breast cancer (TNBC) with defined subsets of autologous T cells expressing a ROR1-specific chimeric antigen receptor (ROR1-CAR) [poster no. P2-09-13]. San Antonio breast cancer symposium (SABCS); 4-8 Dec 2018; San Antonio.

126. Moroz K. Anti-CEA CAR-T demonstrates significant therapeutic effect in pancreatic cancer patients with liver metastases. Interventional Oncology. 2018. https://www.interventionaloncolo gy360.com/news/anti-cea-car-t-demonstrates-significant-thera peutic-effect-pancreatic-cancer-patients-liver. Accessed 16 May 2019.

127. Katz SC, Burga RA, McCormack E, Wang LJ, Mooring W, Point GR, et al. Phase I hepatic immunotherapy for metastases study of intra-arterial chimeric antigen receptor-modified T-cell therapy for CEA+ liver metastases. Clin Cancer Res. 2015;21:3149-59.

128. Katz SC, Prince E, Cunetta M, Guha P, Moody A, Armenio V, et al. HITM-SIR: Phase Ib trial of CAR-T hepatic artery infusions and selective internal radiation therapy for liver metastases [abstract no. CT109]. Cancer Res. 2017;77:CT109.

129. American Cancer Society. Cancer facts \& figures 2019. Atlanta: American Cancer Society; 2019.

130. Hegde M, DeRenzo CC, Zhang H, Mata M, Gerken C, Shree A, Yi Z, Brawley V, Dakhova O, Wu M-F, Liu H, Hicks F, Grilley B, Gee AP, Rooney CM, Brenner MK, Heslop HE, Wels W, Gottschalk S, Ahmed NM. Expansion of HER2-CAR T cells after lymphodepletion and clinical responses in patients with advanced sarcoma. J Clin Oncol. 2017;35(15_suppl):10508. https ://doi.org/10.1200/JCO.2017.35.15_suppl.10508 